\section{Epigenetic regulation of genome integrity by a prion-based mechanism}

\author{
James S. Byers ${ }^{1}$, David M. Garcia ${ }^{2}$, and Daniel F. Jarosz ${ }^{1,2, *}$
}

\title{
Affiliations:
}

${ }^{1}$ Department of Developmental Biology, Stanford University School of Medicine, 269 Campus Drive, Stanford, CA 94305

${ }^{2}$ Department of Chemical and Systems Biology, Stanford University School of Medicine, 269 Campus Drive, Stanford, CA 94305

*To whom correspondence should be addressed: jarosz@stanford.edu 


\section{ABSTRACT}

50

51 Epigenetic mechanisms mediate diverse gene expression programs in growth and development. Yet

52 whether any can permanently alter the genome is unknown. Here we report a protein-based epigenetic

53 element, a prion, formed by the conserved DNA helicase Mph1/FANCM. [MPH1 ${ }^{+}$provides resistance to

54 DNA damage, a gain-of-function trait that requires helicase activity and interactions with other DNA

55 repair proteins. Strikingly, the intrinsically disordered regions of Mph1 and human FANCM that are

56 required for prion phenotypes do not resemble known prions. $\left[\mathrm{MPH}^{+}\right]$reduces mitotic mutation rates,

57 but promotes meiotic crossovers, driving phenotypic diversification in wild outcrosses. Remarkably,

$58\left[\mathrm{MPH}^{+}\right]$is induced by stresses in which the prion is beneficial. Thus, $\left[\mathrm{MPH} 1^{+}\right]$fuels a quasi-Lamarckian

59 form of inheritance that promotes survival of the current generation and diversification of the next.

60 


\section{INTRODUCTION}

62 All organisms must faithfully transmit a genetic blueprint comprising $\sim 10^{6}$ to $\sim 10^{9}$ base pairs to the next

63 generation. This challenge is met by an ancient cohort of proteins that orchestrate error-free replication

64 and DNA repair (Whitby, 2010). Many such activities are organized by a helicase known as Mph1

65 (mutator phenotype 1) in fungi and FANCM (Fanconi Anemia complementation group M) in animals and

66 plants (Crismani et al., 2012; Moldovan and D'Andrea, 2009). Mph1/FANCM also drives diverse

67 biochemical activities including DNA-dependent ATPase function, replication fork reversal, and D loop

68 dissociation (Whitby, 2010). In humans, mutations in FANCM are associated with Bloom's syndrome and

69 elevated cancer rates, underscoring its central importance in ensuring genome integrity (Alter, 1996;

70 Meetei et al., 2003). A hallmark of Fanconi anemia patients is extreme sensitivity to chemotherapeutics

71 that create DNA inter-strand crosslinks or double strand breaks (DSBs) (Moldovan and D'Andrea, 2009).

72 In nature DSBs arise commonly during sexual reproduction, where they serve as intermediates for

73 meiotic recombination, but vastly exceed the number of crossovers in most organisms (McMahill et al.,

74 2007). Recent studies in Arabidopsis thaliana and Schizosaccharomyces pombe suggest that, by

75 suppressing crossover events, Mph1/FANCM provides a molecular explanation for this imbalance

76 (Crismani et al., 2012; Lorenz et al., 2012).

77 Here we report that Mph1 has the capacity to act as protein-based epigenetic element, a prion,

78 that we term $\left[\mathrm{MPH}^{+}\right]$(brackets denote non-Mendelian meiotic segregation; capitalization denotes

79 dominance). $\left[\mathrm{MPH}^{+}\right]$is adaptive during genotoxic stress. It also exerts a strong influence on genome

80 fidelity, decreasing mutagenesis in mitotic growth while increasing the frequency with which DSBs are

81 resolved as crossovers during sexual reproduction. $\left[\mathrm{MPH}^{+}\right]$can be induced by the same stresses to

82 which it provides resistance, providing a molecular mechanism for quasi-Lamarckian inheritance. Our

83 data thus establish $\left[\mathrm{MPH}^{+}\right]$as an inducible epigenetic state that simultaneously guards the genome 
84 against insult during mitotic division and promotes its permanent and heritable diversification during

85 meiosis.

87 Methods

88 Yeast Techniques. Yeast strains (Table S1) were obtained from stock centers or generously provided by

89 the sources indicated. All strains were stored as glycerol stocks at $-80^{\circ} \mathrm{C}$ and revived on YPD before

90 testing. Yeast were grown in YPD at $30^{\circ} \mathrm{C}$ unless indicated otherwise. Yeast transformation was

91 performed with a standard lithium-acetate protocol (Gietz et al., 1992).

92 For yeast crossing experiments, MATa and MATa mating types each lacking a unique

93 auxotrophic marker were mixed overnight in YPD. This mixture was then plated on plates selecting for

94 these 2 auxotrophies to select for diploids (usually minus lysine and minus methionine). After 3 days,

95 colonies were picked and grown in $8 \mathrm{mLs}$ pre-sporulation media (8 g Yeast Extract, $3 \mathrm{~g}$ Bacto Peptone,

$96100 \mathrm{~g}$ Dextrose, $100 \mathrm{mg}$ adenine sulfate per liter) overnight. The next morning, the cells were washed

97 and resuspended in $3 \mathrm{mLs}$ sporulation media (10 g potassium acetate, $1 \mathrm{~g}$ yeast extract, $0.5 \mathrm{~g}$ glucose,

$980.1 \mathrm{~g}$ amino acid add-back per liter). Cells were incubated for 7 days at room temperature and spores

99 were enriched as described previously (Rockmill et al., 1991).

100 Cytoduction experiments were performed as described previously (Chakrabortee et al., 2016).

101 Briefly, initial BY4742 recipient strains generated by transformation introducing a defective KAR allele

102 (kar1-15) that prevents nuclear fusion during mating (Wickner et al., 2006). Strains were made 'petite'

103 (incompetent for mitochondrial respiration) by inoculating a single colony in YPD with $0.25 \%$ ethidium

104 bromide and growing culture at $30{ }^{\circ} \mathrm{C}$ until late exponential/stationary phase $\left(\mathrm{OD}_{600} \sim 1\right)$. Cultures were

105 diluted 1:1000 into fresh YPD with ethidium bromide and the previous steps were repeated twice.

106 Cultures were plated to single colonies and multiple were tested for respiration incompetence (i.e. no

107 growth on YP-Glycerol). For initial cytoduction into BY4742, donor BY4741 strains harboring $\left[\mathrm{MPH1}^{+}\right]$ 
108 and naïve BY4742 kar1-15 recipient strains were mixed on the surface of a YPD agar plate. These were

109 grown for 24 hours and transferred to media lacking methionine and containing glycerol as a carbon

110 source (SGly-MET). This selects for both BY4742 nuclear markers along with restoration of functional

111 mitochondria via cytoplasmic exchange. After 3-5 days, multiple single colonies were picked and

112 passaged with another round of selection on SD-MET. In parallel, these colonies were confirmed to be

113 haploid by passage on SD-LYS-MET medium. For reverse cytoductions, the new donor strains (this time

114 the successful BY4742 kar1-15 cytoductants) were mixed with petite naïve BY4741 cells (generated as

115 above) on YPD agar. Cytoductions were repeated as described previously except selecting for BY4741

116 recipient nuclear markers on glycerol media lacking lysine (SGly-LYS). Multiple cytoductants were picked

117 and tested for the presence of $\left[\mathrm{MPH1}^{+}\right]$phenotypes.

119 Phenotypic assays. Biological replicates of each yeast strain (BY4741 MATa haploids) were pre-grown in

120 rich media (YPD). We then diluted these saturated cultures 1:10 in sterile water and then inoculated 1.5

$121 \mu \mathrm{L}$ into 96-well plates with $150 \mu \mathrm{L}$ of YPD (SD-CSM was used instead with cisplatin and mitomycin C) per

122 well with the following stressors: phleomycin $5 \mu \mathrm{g} / \mathrm{mL}$; mycophenolic Acid - $20 \mu \mathrm{M}$; hydroxyurea -400

$123 \mathrm{mM}$; 4-nitroquinoline 1-oxide - $1.2 \mu \mathrm{M}$; cisplatin - $8 \mathrm{mM}$; methyl methanesulfonate $-0.012 \%$;

124 camptothecin $-50 \mu \mathrm{M}$; doxorubicin $-80 \mu \mathrm{M}$; oxolinic acid - $100 \mu \mathrm{M}$; mitomycin $\mathrm{C}-1 \mathrm{mM}$. We grew cells

125 at $30{ }^{\circ} \mathrm{C}$ in humidified chambers for $96 \mathrm{~h}$ and continuously measured growth by $\mathrm{OD}_{600}$ in a microplate

126 reader. Timepoints plotted in bar graphs correspond to the point of greatest difference between [ $\mathrm{mph}^{-}$

127 ] and $\left[\mathrm{MPH}^{+}\right]$: phleomycin - $1225 \mathrm{~min}$; mycophenolic Acid - $755 \mathrm{~min}$; hydroxyurea - $2500 \mathrm{~min}$; 4-

128 nitroquinoline 1-oxide - 2500 min; methyl methanesulfonate - 1600 min; camptothecin - 900 min;

129 doxorubicin - 2000 min; oxolinic acid - 755 min; mitomycin C - 2500 min.

$130 \quad$ For genetic interaction experiments, phenotyping was performed similarly to before but instead

131 in 384-well plates to generate additional technical replicates for each strain. Briefly, biological replicates 
132 of each knockout were pre-grown in rich media (YPD) in 96-well plates. We did not analyze mutants of

133 two additional interacting proteins, Rfa1 and Smc5, which were associated with strong sporulation

134 defects unrelated to the prion (Farmer et al., 2011; Soustelle et al., 2002)). We then diluted these

135 saturated cultures 1:10 in sterile water and then inoculated $5 \mu \mathrm{L}$ in a 1:4 array into 384-well plates with

$13645 \mu \mathrm{L}$ of YPD+4-NQO per well. However, because each genetic knockout was differentially sensitive to

137 genotoxic stress, different concentrations of the chemical were used for each genotype: $\operatorname{rad} 5 \Delta-2 \mu \mathrm{M}$;

$138 \operatorname{rad} 51 \Delta-1.5 \mu \mathrm{M} ; \operatorname{sgs} 1 \Delta-1 \mu \mathrm{M} ; \operatorname{srs} 2 \Delta-2 \mu \mathrm{M} ; \operatorname{mhf} 1 \Delta-1.5 \mu \mathrm{M} ; \operatorname{mhf} 2 \Delta-2 \mu \mathrm{M} ; \operatorname{ch} / 1 \Delta-2 \mu \mathrm{M} ;$ exo1 $1 \Delta-$

$1391.5 \mu \mathrm{M} ; m g m 101 \Delta-1 \mu \mathrm{M} ; m s h 2 \Delta-1 \mu \mathrm{M} ; m s h 6 \Delta-2 \mu \mathrm{M} ;$ pso2 $\Delta-1.5 \mu \mathrm{M} ;$ slx4 $\Delta-2 \mu \mathrm{M}$. We grew cells

140 at $30{ }^{\circ} \mathrm{C}$ in humidified chambers for $96 \mathrm{~h}$ and continuously measured growth by $\mathrm{OD}_{600}$ in a microplate

141 reader. The Log2 fold-change values plotted correspond to the highest $\mathrm{OD}_{600}$ value reached for each

142 strain (i.e. the carrying capacity). The same concentrations were used for the phenotyping of the

143 corresponding heterozygous, cross-back diploids.

144

145 Microscopy. Microscopy was performed using a Leica inverted fluorescence microscope with a

146 Hammamatsu Orca 4.0 camera. Cells were imaged after growth to exponential phase (OD600 of 0.7) or

147 stationary phase (OD 1.5 or above after 2 days) in a medium that minimizes autofluorescence (per liter

148 in water: $6.7 \mathrm{~g}$ yeast nitrogen base without ammonium sulfate, $5 \mathrm{~g}$ casamino acids, $20 \mathrm{~g}$ glucose).

149 Exposure time was 2 seconds.

150

151 Protein Transformation. Lysate transformations were performed as described previously (Chakrabortee

152 et al., 2016; Tanaka and Weissman, 2006). Briefly, $50 \mathrm{~mL}$ cultures of $\left[\mathrm{MPH}^{+}\right]$strains were grown in YPD

153 for $18 \mathrm{~h}$, pelleted, washed twice with $\mathrm{H}_{2} \mathrm{O}$ and $1 \mathrm{M}$ sorbitol respectively, and then resuspended in $200 \mu \mathrm{L}$

154 of SCE buffer (1 M sorbitol, $10 \mathrm{mM}$ EDTA, $10 \mathrm{mM}$ DTT, 100mM sodium citrate, 1 Roche mini-EDTA-free

155 protease inhibitor tablet per $50 \mathrm{~mL}, \mathrm{pH}$ 5.8) containing 50 units $/ \mathrm{mL}$ of zymolyase $100 \mathrm{~T}$. Cells were 
156 incubated for $30 \mathrm{~min}$ at $35^{\circ} \mathrm{C}$, sonicated on ice for $10 \mathrm{~s}$ with a sonic dismembrator at $20 \%$ intensity, and

157 cell debris was removed via centrifugation at $10,000 \mathrm{~g}$ at $4^{\circ} \mathrm{C} \times 15 \mathrm{~min}$. Supernatants were digested with

158 3-fold excess RNAse I and biotinylated DNAse (as determined by units of activity) (Thermo AM1906) for

$1591 \mathrm{~h}$ at $37^{\circ} \mathrm{C}$. DNase was subsequently removed by adding saturating quantities of streptavidin-sepharose

160 beads, incubating for $5 \mathrm{~min}$, and bead pelleting via centrifugation (this allows addition of a URA3-

161 marked plasmid for selection later). Nuclease digested supernatants were used to transform naïve

162 recipient yeast spheroplasts. Cells were harvested as before, re-suspended in $200 \mathrm{U} / \mathrm{mL}$ zymolyase $100 \mathrm{~T}$

163 in $1 \mathrm{M}$ sorbitol, and incubated at $35^{\circ} \mathrm{C}$ for $15 \mathrm{~min}$. Spheroplasts were collected by centrifugation, and

164 washed twice with $1 \mathrm{~mL}$ sorbitol and $1 \mathrm{~mL} \mathrm{STC}$ buffer ( $1 \mathrm{M}$ sorbitol, $10 \mathrm{mM} \mathrm{CaCl}, 10 \mathrm{mM}$ Tris pH 7.5)

165 respectively, and re-suspended in STC buffer using wide-mouthed pipet tips to avoid lysis. Aliquots of 166 spheroplasts were transformed with $50 \mu \mathrm{L}$ of lysate, $20 \mu \mathrm{L}$ salmon sperm DNA $(2 \mathrm{mg} / \mathrm{mL})$, and $5 \mu \mathrm{L}$ of a

167 carrier plasmid (URA3- and GFP-expressing pAG426-GFP). Spheroplasts were incubated in

168 transformation mix for $30 \mathrm{~min}$ at room temperature, collected via centrifugation, and resuspended in

$169150 \mu \mathrm{L}$ of SOS-buffer ( $1 \mathrm{M}$ sorbitol, $7 \mathrm{mM} \mathrm{CaCl}, 0.25 \%$ yeast extract, $0.5 \%$ bacto-peptone). Spheroplasts

170 were recovered at $30^{\circ} \mathrm{C}$ for $30 \mathrm{~min}$ and the entire culture was plated on SD-URA plates and overlaid with

171 warm SD-CSM containing $0.8 \%$ agar. After 2-3 days, dozens of Ura+ colonies were picked and re-

172 streaked on SD-URA selective media. The carrier plasmid was subsequently removed by section on 5-

$173 \mathrm{FOA}$ and single colonies were tested for the transmission of $\left[\mathrm{MPH}^{+}\right]$-dependent phenotypes. Infectivity

174 is calculated as percent of transmission divided by the amount of seeded protein used (estimate 77

175 molecules/cell of Mph1) (Kulak et al., 2014).

177 Mutagenesis assays. Yeast strains were grown in multiple biological replicates to saturation in YPD.

178 Then $1 \mathrm{~mL}$ was spun down, resuspended in $100 \mu \mathrm{L} \mathrm{H} \mathrm{H}_{2} \mathrm{O}$, and plated on SD-Arg (6.7 g yeast nitrogen base

179 without ammonium sulfate, $5 \mathrm{~g}$ casamino acids without arginine, $20 \mathrm{~g}$ glucose per liter) $+60 \mu \mathrm{g} / \mathrm{mL}$ 
180 Canavanine (forward mutagenesis), YPD + $100 \mu \mathrm{M}$ Fluconazole, or $60 \mu \mathrm{g} / \mathrm{mL}$ Canavanine and $1 \mathrm{~g} / \mathrm{L} \mathrm{5-}$

181 Fluoroorotic acid (GCR mutagenesis). Plates were incubated for 3 days and then CFUs were counted 182 using a colony counter (Synbiosis Acolyte).

184 Induced mutagenesis and prion switching assays. Yeast strains (BY4741 or MDG1::K.lactisURA3

185 reporter strains) were grown with 3 biological replicates to saturation in YPD with the indicated

186 chemicals for induced mutagenesis frequencies $\left(0.012 \% \mathrm{MMS}, 100 \mu \mathrm{M}\right.$ Oxolinic Acid) or for $\left[\mathrm{MPH}^{+}\right]$

187 reporter switching $\left(2.4 \mu \mathrm{M}\right.$ 4-NQO, $400 \mu \mathrm{M}$ Camptothecin, $2 \mathrm{mM}$ Cisplatin, $0.024 \% \mathrm{H}_{2} \mathrm{O}_{2}, 400 \mathrm{mM}$

188 Hydroxyurea, $0.012 \% \mathrm{MMS})$. For starvation conditions in $\left[\mathrm{MPH}^{+}\right]$reporter switching, yeast strains were

189 grown with 3 biological replicates to saturation in YPD and then washed once with water and

190 resuspended in the following media conditions (no glucose, nitrogen limitation, phosphate limitation,

191 and sporulation media). Then $1 \mathrm{~mL}$ was spun down, resuspended in $100 \mu \mathrm{L} \mathrm{H}_{2} \mathrm{O}$, and plated on the

192 indicated selective plates: SD-Arg (6.7 g yeast nitrogen base without ammonium sulfate, $5 \mathrm{~g}$ casamino

193 acids without arginine, $20 \mathrm{~g}$ glucose per liter) $+60 \mu \mathrm{g} / \mathrm{mL}$ Canavanine (forward mutagenesis) or SD-URA

194 (50 mg uracil, $6.7 \mathrm{~g}$ yeast nitrogen base without ammonium sulfate, $5 \mathrm{~g}$ casamino acids, $20 \mathrm{~g}$ glucose per

195 liter) $+1 \mathrm{~g} / \mathrm{L}$ 5-FOA (reporter switching). Plates were incubated for 3 days and then CFUs were counted

196 using a colony counter (Synbiosis Acolyte). For prion reporter switching, MDG1 has no defined function

197 in mutagenesis or DNA repair, but is down-regulated in $\left[\mathrm{MPH1}^{+}\right]$cells. Thus, $\left[\mathrm{mph1} 1^{-}\right]$cells can grow on

198 media lacking uracil, but $\left[\mathrm{MPH}^{+}\right]$cells cannot. In contrast, $\left[\mathrm{MPH1}^{+}\right]$cells can grow on $5-\mathrm{FOA}$, whereas

$199\left[m p h 1^{-}\right]$cells cannot.

201 Meiotic Recombination Assays. Meiotic reporter strains were generated by amplifying a K.lactis URA3

202 cassette off the pUG72 plasmid (Euroscarf) with primers targeting the marker $50 \mathrm{~kb}$ upstream of the

203 his $3 \Delta$ locus of BY4741. These PCR products were transformed into [ $\left.m p h 1^{-}\right],\left[\mathrm{MPH1}^{+}\right]$, and $m p h 1 \Delta$ strains 
204 as described above. A functional HIS3 marker was also re-integrated back into its endogenous locus via

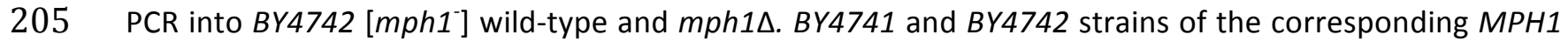

206 genotype were crossed to generate His+ Ura+ diploids and then sporulated as described above. Dozens

207 of colonies were picked for each and tested for co-segregation of URA3 and HIS3 markers.

208 For the genetic cross experiments with lab and clinical strains, the [mph1'] and $\left[\mathrm{MPH}^{+}\right]$

209 laboratory strains above were crossed to the clinical isolate YJM975 (SGRP). Diploids were sporulated as

210 before and then 96 spores were picked for each. Spores were pinned in quadruplicate onto solid YPD

211 plates with the follower stressors: $39^{\circ} \mathrm{C}, 128 \mu \mathrm{g} / \mathrm{mL}$ fluconazole, $1 \mathrm{mM}$ amphotericin $\mathrm{B}, 120 \mu \mathrm{g} / \mathrm{mL}$

212 calcofluor white, $0.01 \% \mathrm{H}_{2} \mathrm{O}_{2}$. Yeast were grown at $30^{\circ} \mathrm{C}$ (except in the case of $39^{\circ} \mathrm{C}$ heat stress) for $3-4$

213 days and then pictures were taken and colony size analysis was conducted using SGAtools (Wagih et al.,

214 2013). Distributions were normalized to the means of the population.

215

216

217

218

219

220

221

222

223

224

225

226

227 


\section{RESULTS}

\section{$229\left[\mathrm{MPH1}^{+}\right]$is a protein-based genetic element}

230 We previously found that transient overexpression of Mph1 could elicit heritable zinc resistance that

231 had properties consistent with protein-based inheritance (Chakrabortee et al., 2016). These included

232 non-Mendelian segregation of this phenotype in genetic crosses (it was inherited by all meiotic progeny

233 rather than half), and a strong reliance on molecular chaperones (Hsp70 proteins) for propagation from

234 one generation to the next. This chaperone dependence was unusual - most previously known prions

235 depend on Hsp104 to propagate (Shorter and Lindquist, 2005) - and Mph1 lacks the glutamine or

236 asparagine-rich regions typical of nearly all known prions. We therefore investigated whether this

237 Mph1-dependent epigenetic state was a bona fide protein-based genetic element.

238 Prion acquisition commonly elicits heritable changes in the localization of causal protein(s)

239 (Derkatch et al., 2001). We investigated whether this was true for the Mph1-dependent epigenetic

240 state, taking advantage of the fact that prions are dominant (Shorter and Lindquist, 2005). We crossed a

241 yeast strain expressing an endogenous MPH1-YFP fusion to a strain harboring the Mph1-dependent

242 epigenetic state, and to genetically identical (isogenic) naïve cells as a control. There was no apparent

243 difference between these groups in exponentially growing cells. However, in stationary phase cells,

244 Mph1-YFP foci were evident in diploids harboring the Mph1-dependent epigenetic state, but not in

245 isogenic naïve diploids (Fig. S1).

246 We next tested whether the Mph1-dependent epigenetic state could be transmitted by

247 cytoplasmic mixing without transfer of any nuclear material, another hallmark of prion biology (Wickner

248 et al., 2006). To do so, we performed 'cytoduction' experiments with kar1-15 mutants in which nuclei do

249 not fuse during mating (Fig. S2A; see methods). The Mph1-dependent epigenetic state was robustly

250 transferred to naïve recipient cells through such 'cytoduction' experiments (Fig. S2B). These data thus

251 establish that the phenotype did not arise from genetic mutation. 
Finally, we performed a protein transformation as the 'gold-standard' test for prion-based

253 inheritance. We generated nuclease-digested lysates from cells harboring the Mph1-dependent

254 epigenetic state and from isogenic naïve cells. We used these lysates to transform naïve spheroplasts

255 (yeast lacking a cell wall), including a carrier plasmid harboring a URA3 marker to enrich for cells that

256 were competent to uptake molecules from their external milieu (Fig. S2C; see methods). We picked

257 dozens of Ura+ colonies, propagated them on 5-FOA to select for loss of the carrier plasmid, and

258 characterized the phenotypes of the resulting cells. Strikingly, over $40 \%$ of them also acquired the

259 Mph1-dependent epigenetic state (scored by resistance to $\mathrm{ZnSO}_{4}$; Fig. $1 \mathrm{~A} ; p=1.6 \times 10^{-4}$ by t-test). When

260 benchmarked against the low natural abundance of Mph1 ( 80 molecules per cell (Kulak et al., 2014)),

261 this frequency of transmission is substantially more efficient than for other prions that have been tested

262 (Tanaka and Weissman, 2006). We conclude that the Mph1-dependent epigenetic state is a bona fide

263 protein-based genetic element - a prion - which we hereafter refer to as $\left[\mathrm{MPH}^{+}\right]$.

\section{$265\left[\mathrm{MPH1}^{+}\right]$promotes DNA damage tolerance and genome stability}

266 Because Mph1 plays a central role in genome integrity we tested the ability of $\left[\mathrm{MPH}^{+}\right]$cells to

267 withstand DNA damage. The prion had no effect on growth in rich medium alone. We next exposed

$268\left[\mathrm{mph}^{-}\right],\left[\mathrm{MPH}^{+}\right]$, and $m p h 1 \Delta$ cells to a battery of genotoxic insults, including replication stressors

269 (hydroxyurea, mycophenolic acid), intercalating agents (doxorubicin), lesion inducers (4-NQO), alkylating

270 agents (MMS), topoisomerase inhibitors (oxolinic acid), DNA break inducers (phleomycin), and

271 crosslinkers (cisplatin, camptothecin, mitomycin C). In most of these conditions, cells harboring $\left[\mathrm{MPH}^{+}\right]$

272 grew better than isogenic [mph1'] cells, and the prion was never maladaptive (Fig. 1B). In contrast,

273 mph1 $1 \Delta$ cells were hypersensitive to most genotoxic stressors. Many amyloid-based prions act by

274 sequestering their constituent protein into aggregates. Thus their phenotypes often mimic the 
275 corresponding genetic loss-of-function. Our data indicate that $\left[\mathrm{MPH}^{+}\right]$is capable of driving gain-of-

276 function phenotypes.

277 Mph1 overexpression strongly increases the frequency of gross chromosomal rearrangements

278 (GCR) and, conversely, mph1s decreases GCR formation (Banerjee et al., 2008). We observed no

279 influence of $\left[\mathrm{MPH}^{+}\right]$on GCRs using the same reporter strains employed in those studies ( $p=0.40$ by

280 Student's t-test, Fig. S3) however, establishing that the prion state is distinct from a simple increase in

281 Mph1 activity. We also examined mutagenesis using an assay in which loss-of-function mutations in the

282 CAN1 gene render cells resistant to the toxic arginine analog canavanine. As others have reported

283 (Scheller et al., 2000), mph1s cells had an approximately tenfold increased spontaneous mutagenesis

284 frequency compared to wild-type cells. In contrast, $\left[\mathrm{MPH}^{+}\right]$cells had a three-fold decreased frequency

285 of spontaneous mutation compared to isogenic [mph1'] cells (Fig. 1C), again consistent with [MPH1 $\left.{ }^{+}\right]$

286 driving gains-of-function. We observed the same anti-mutator phenotype when scoring resistance to the

287 antifungal drug fluconazole (Fig. 1D), establishing that these relationships were not unique to the

288 forward mutagenesis assay employed. We also observed decreased frequencies of induced mutagenesis

289 in $\left[\mathrm{MPH1}^{+}\right]$cells (e.g. with MMS and oxolinic acid; Fig. 1C).

290 One possible explanation for the decreased mutation frequency in $\left[\mathrm{MPH}^{+}\right]$cells would be

291 preferential engagement of error-free repair pathways, which often involve homologous recombination.

292 Indeed, Mph1 has been implicated in pathway choice decisions in multiple organisms (Huang et al.,

293 2013; Xue et al., 2015b) and [ $\left.\mathrm{MPH}^{+}\right]$provides resistance to agents that induce DSBs (e.g. phleomycin;

294 Fig. 1B), which serve as precursors to HR. Using a simple assay for integration of a HIS3 marker at its

295 endogenous locus (see methods), we found that $\left[\mathrm{MPH1}^{+}\right]$drives a robust increase in HR (5.3-fold;

$296 p=0.003$ by t-test; Fig. S4), providing a possible explanation for the reduced mutagenesis frequency.

297 Collectively, our data establish that $\left[\mathrm{MPH}^{+}\right]$enhances survival and preserves genome integrity during

298 wide range of genotoxic insults. 
$300\left[\mathrm{MPH}^{+}\right]$phenotypes require helicase function

301 The gains-of-function in $\left[\mathrm{MPH1}^{+}\right]$cells led us to investigate whether Mph1's catalytic activity was

302 required for prion-dependent phenotypes. To test this, we employed a well-characterized inactivating

303 point mutation in Mph1's active site (mph1-Q603D, (Chen et al., 2009)). We crossed isogenic [MPH1 $\left.{ }^{+}\right]$

304 and [ $\left.\mathrm{mph}^{-}\right]$cells to a naïve strain harboring $m p h 1-Q 603 D$, selected diploids, sporulated them, and then

305 examined meiotic progeny that harbored the mph1-Q603D alleles (Fig. 2A).

306 As expected, $\left[\mathrm{MPH}^{+}\right]$progeny harboring the wild-type allele were more resistant to 4-NQO than

307 matched $\left[\mathrm{mph1}^{-}\right]$progeny $(\mathrm{p}=0.014$ by t-test, Fig. $2 \mathrm{~B})$. In contrast, $\left[\mathrm{MPH1}^{+}\right]$progeny harboring the $\mathrm{mph1-}$

308 Q603D allele were as sensitive to 4-NQO as [ $\left.\mathrm{mph}^{-}\right]$progeny harboring the catalytically inactive variant

309 ( $p=0.21$, Fig. $2 \mathrm{~B})$. Thus, Mph1 activity is required to produce $\left[\mathrm{MPH}^{+}\right]$phenotypes. We tested whether

310 Mph1 catalytic function was also required for prion propagation (Fig. 2A). To do so we crossed meiotic

311 progeny (arising from the previous cross) harboring the mph1-Q603D allele to naïve, wild-type strains to

312 create heterozygous diploids in which Mph1 function was restored. Prion-dependent resistance to 4-

313 NQO re-emerged in these strains ( $p=0.047$ by t-test, Fig. 2B), establishing that the helicase function of

314 Mph1 is required to produce DNA damage resistance, but not to propagate the prion itself.

\section{$316\left[\mathrm{MPH1}^{+}\right]$phenotypes require FA pathway components}

317 As a scaffold, Mph1 interacts with many factors involved in both error-free and error-prone DNA repair

318 (Daee et al., 2012; Ward et al., 2012; Xue et al., 2015a). We applied classical epistasis to examine how

319 these interactions influence $\left[\mathrm{MPHI}^{+}\right]$-dependent phenotypes, capitalizing on the fact that $\left[\mathrm{MPHI}^{+}\right]$is

320 transmitted to all progeny of meiosis (Chakrabortee et al., 2016). We crossed isogenic $\left[\mathrm{MPH}^{+}\right]$and

$321\left[\mathrm{mph}^{-}\right]$cells to naïve strains harboring deletions of thirteen previously reported Mph1-interacting

322 genes, related helicases, proteins involved in inter-strand crosslink (ICL) repair, and FA pathway 
323 components. We then sporulated these diploids and selected six $\left[\mathrm{MPH}^{+}\right]$and $\left[\mathrm{mph1}^{-}\right]$progeny

324 harboring each gene deletion. Finally, we exposed these strains to genotoxic stress and compared how

$325\left[\mathrm{MPHI}^{+}\right]$affected survival in the context of each gene deletion.

326 We observed strong genetic interactions between $\left[\mathrm{MPH}^{+}\right]$and components of the FA pathway.

327 This network has been best characterized in the context of ICL repair, where Mph1 scaffolds

328 Msh2/Msh6 to recruit Exo1 and digest the ICL-harboring oligonucleotide. Mhf1/Mhf2 stabilizes Mph1

329 complexes on chromatin at stalled replication forks and Chl1 (the yeast FancJ homolog) and Slx4 (the

330 yeast FancP homolog) mediate downstream gap re-filling and fork reset (Daee et al., 2012). Loss of each

331 of these FA factors eliminated $\left[\mathrm{MPH}^{+}\right]$-dependent resistance to genotoxic stress (Fig. 2C).

332 Deletion of two genes encoding proteins related to Mph1/ICL repair, Pso2 (a nuclease and

333 member of an orthogonal ICL epistasis group) (Ward et al., 2012) and Srs2 (the yeast RTEL1 helicase

334 homolog), abolished the $\left[\mathrm{MPH}^{+}\right]$phenotype, even though they are not linked to the FA pathway (Daee

335 et al., 2012). These epistasis patterns establish that the phenotypic effects of $\left[\mathrm{MPH}^{+}\right]$require

336 engagement of most yeast Fanconi proteins (Ward et al., 2012), as well as other factors that are thought

337 to function in independent, parallel repair pathways (Fig. $2 \mathrm{C}$ ), raising the possibility that $\left[\mathrm{MPH} 1^{+}\right]$exerts

338 its phenotypes by re-wiring crosstalk among DNA repair factors.

339 We next tested whether these Mph1 interactions were required for prion propagation. To do so

340 we crossed the haploid deletion strains in which $\left[\mathrm{MPH}^{+}\right]$-dependent phenotypes had disappeared to

341 naïve wild-type strains, creating heterozygous diploids in which gene function was restored. Strikingly,

342 resistance to genotoxic stress re-emerged in only 3 strains: exo1 $\triangle / E X O 1, \operatorname{rad} 5 \Delta / R A D 5$, and

343 mgm1014/MGM101 (Fig. 2C). Thus, the remaining proteins (Rad51, Srs2, Mhf1, Mhf2, Chl1, Msh2,

344 Msh6, Pso2, Slx4), which include most of the FA pathway, are required not only to manifest $\left[\mathrm{MPH}^{+}\right]$

345 phenotypes, but also to propagate the prion.

346 Genetic requirements for mutagenesis and survival in DNA damage can differ. We therefore 
347 investigated how the loss of these same genes affected the anti-mutator phenotype of [MPH1 $\left.{ }^{+}\right]$. (This

348 was only possible in haploids because most canavanine resistant mutants are recessive.) Cells lacking

$349 \mathrm{Mgm101}$, Pso2, and Rad51 inherited anti-mutator phenotypes from an $\left[\mathrm{MPH}^{+}\right]$parent (Table S3), but

350 those lacking Rad5, Msh2, Msh6, or Mhf1 did not inherit an anti-mutator phenotype. Strikingly, $\left[\mathrm{MPH1}^{+}\right]$

351 led to large increases in mutation frequency in strains lacking Slx4 and Mhf2. Mhf2 stabilizes aberrant

352 DNA structures, allowing helicases such as Mph1 to remodel them. Slx4 is a structure-specific

353 endonuclease that also acts on aberrant DNA structures (particularly branched substrates) (Fricke and

354 Brill, 2003). Slx4 has overlapping specificity with another DNA helicase, Sgs1 (BLM in humans), which

355 interacts with topoisomerase 3 to process stalled replication forks (Fricke and Brill, 2003). As with Slx4,

356 loss of Sgs1 also led to a strong mutator phenotype in the presence of [ $\left.\mathrm{MPH}^{+}\right]$. Our data thus strongly

357 suggest that the anti-mutator phenotype in $\left[\mathrm{MPH}^{+}\right]$cells depends on Slx4, Sgs1, and Mhf2 activities,

358 and likely their ability to resolve aberrant DNA intermediates in a non-mutagenic fashion.

359

360 Prion-dependent toxicity of Mph1 and FANCM overexpression

361 A hallmark of many prion proteins is that they can be toxic when overexpressed in matched [PRION $\left.{ }^{+}\right]$

362 strains, but not in naïve cells (Fig. 3A). This toxicity typically requires specific protein domains that are

363 important for prion propagation (Douglas et al., 2008). Mph1 overexpression from a constitutive

364 promoter was indeed significantly more toxic in $\left[\mathrm{MPH}^{+}\right]$cells than in [ $\left.\mathrm{mph} 1^{-}\right]$cells $(p=0.04$ by t-test, Fig.

365 3B). We used this growth impairment as a tool to dissect which domains of Mph1 fuel its prion-like

366 properties. Mph1 does not harbor N/Q-rich prion-like domains (Fig. 3C). However, it does contain

367 multiple, large, extremely disordered regions outside of its helicase domain (Jones and Cozzetto, 2015)

368 (Fig. 3D), particularly at the C-terminus. This pattern of disorder is highly conserved in the human

369 ortholog FANCM (Fig. 3D), and truncation of the disordered C-terminal region is the most frequent

370 FANCM variant observed in human cancers (Cerami et al., 2012). Notably, Mph1 variants lacking its large 
371 C-terminal disordered region did not exert prion dependent toxicity (Fig. 3B), despite similar levels of

372 expression (Fig. S5), establishing the importance of this disordered region in prion-dependent 373 phenotypes.

374 We also transformed $\left[\mathrm{mph1}^{-}\right]$cells and $\left[\mathrm{MPH1}^{+}\right]$cells with plasmids encoding full-length FANCM

375 and a variant lacking its disordered C-terminus (FANCM $\triangle C$ ) under the control of the same constitutive

376 promoter. Expression of full-length FANCM was also more toxic in $\left[\mathrm{MPH1}^{+}\right]$cells than in isogenic $\left[\mathrm{mph}^{-}\right]$

377 cells ( $p=0.036$ by t-test, Fig. $3 \mathrm{~B}$ ). In contrast, FANCM $\Delta \mathrm{C}$ did not affect growth of either [ $\left.\mathrm{mph}^{-}{ }^{-}\right]$or

$378\left[\mathrm{MPH}^{+}\right]$cells $(p=0.47$ by t-test, Fig. $3 \mathrm{~B})$. Thus, despite its limited sequence identity, human FANCM

379 appears to interact with yeast $\left[\mathrm{MPH}^{+}\right]$to exert a toxicity that depends upon both its disordered C-

380 terminus and the presence of the prion.

381

382 Induction by environmental stress

383 It has been suggested that prions might drive a quasi-Lamarckian form of inheritance (Halfmann et al.,

384 2010; True and Lindquist, 2000), fueling heritable and adaptive phenotypic changes in response to

385 transient environmental stressors (Holmes et al., 2013). Many prions can be modestly induced by

386 perturbations that disrupt protein homeostasis (Jarosz et al., 2010). Yet only two, [GAR ${ }^{+}$(Jarosz et al.,

387 2014) and $\left[\mathrm{MOD}^{+}\right]$(Suzuki et al., 2012), are known to be induced by the same stresses to which they

388 provide resistance. We tested whether any of the DNA damaging stresses in which $\left[\mathrm{MPHI}^{+}\right]$provides a

389 benefit might also elicit its appearance, as would be expected for a Lamarckian epigenetic element. We

390 did so using an MDG1::URA3 reporter that we previously established provides a readout of the $\left[\mathrm{MPH1}^{+}\right]$

391 prion state (Chakrabortee et al., 2016) (Fig. 4A).

392 Exposure to hydroxyurea increased the frequency of $\left[\mathrm{MPHI}^{+}\right]$acquisition seven-fold in these

393 experiments ( $p=0.035$ by $t$-test; Fig. $4 B$ ). We observed no such effect for many other DNA damaging

394 agents in which $\left[\mathrm{MPH}^{+}\right]$provides an equivalent or greater adaptive advantage. These data establish 
395 that the increased frequency of $\left[\mathrm{MPH}^{+}\right]$did not merely arise from selection for the prion. Starvation for

396 another nutrient, phosphate, also strongly induced $\left[\mathrm{MPH}^{+}\right]$(6.4-fold, $\mathrm{p}=0.041$ by $\mathrm{t}$-test). Both

397 hydroxyurea and phosphate starvation have been linked to replication stress via depletion of

398 deoxynucleotide pools (Young et al., 1967). Thus, $\left[\mathrm{MPH1}^{+}\right]$can be induced not just by overexpression, as

399 we did artificially, but also by a specific replication stressor to which it provides resistance, establishing

400 that this prion can act as a quasi-Lamarckian element of inheritance.

401 Because replication stresses acted as a trigger for $\left[\mathrm{MPH}^{+}\right]$, we wondered whether intermediate

402 structures in DNA repair processes might be important for templating and/or propagating the prion.

403 Mph1 binds to specific DNA fork structures to assemble larger complexes at sites of damage (Xue et al.,

404 2015b). Furthermore, other types of nucleic acids have been hypothesized to act as scaffolds for prion-

405 like aggregation in amyloid bodies (Audas et al., 2016). Constitutive overexpression of Mph1 also leads

406 to a mutator phenotype (Banerjee et al., 2008) that depends upon inactivation of another specialized

407 DNA helicase, Pif1, which efficiently unwinds a type of DNA secondary structure known as G-

408 quadruplexes (Paeschke et al., 2013). These guanine repeats form a stable planar structure through

409 hydrogen bonding, which impedes their traversal by the replication machinery. We transiently

410 overexpressed PIF1 for $\sim 25$ generations in $\left[\mathrm{MPHI}^{+}\right]$and $\left[\mathrm{mph1}^{-}\right]$cells and investigated whether they

411 maintained $\left[\mathrm{MPH}^{+}\right]$-dependent decreases in mutagenesis. Immediately following PIF1 overexpression,

$412\left[\mathrm{MPH}^{+}\right]$-dependent decreases in mutagenesis were completely abolished ( $p=0.40$ by t-test, Fig. $4 \mathrm{C}$.).

413 However, after we removed the PIF1 plasmid and propagated the strains 3 times on standard rich

414 medium (YPD) the $\left[\mathrm{MPH}^{+}\right]$-dependent mutagenic phenotypes re-emerged ( $p=0.027$ by t-test, Fig. $4 \mathrm{C}$ ).

415 These results indicate that specific DNA structures, such as G-quadruplex regions or perhaps other Pif1

416 substrates, may play a central role in the manifestation of the $\left[\mathrm{MPH}^{+}\right]$phenotype, but are not required 417 for propagation of the prion. 
$\left[\mathrm{MPH1}^{+}\right]$increases genetic and phenotypic diversification during meiosis

420 Experiments in Arabidopsis thaliana (Crismani et al., 2012) and Schizosaccharomyces pombe (Lorenz et

421 al., 2012) have identified Mph1/FANCM as the strongest known inhibitor of crossover formation during

422 meiosis. We therefore tested whether $\left[\mathrm{MPH1}^{+}\right]$exerted any influence on meiotic crossovers in $S$.

423 cerevisiae. To do so we constructed a yeast strain harboring a functional URA3 cassette 50kb upstream

424 of a non-functional his $3 \Delta 1$ mutation, enabling us to examine co-segregation of these linked genetic

425 markers (Fig. 5A). We mated this strain, which could grow on media lacking uracil but not on media

426 lacking histidine, to isogenic $\left[\mathrm{MPH1}^{+}\right]$and $\left[\mathrm{mph1}^{-}\right]$strains, which harbored a non-functional ura3 $\Delta 0$, but

427 an intact HIS3 locus. We then selected diploids and induced meiosis. There was no difference in

428 sporulation efficiency between $\left[\mathrm{mph}^{-}\right]$and $\left[\mathrm{MPH}^{+}\right]$harboring cells ( $p=0.45$ by Student's t-test, Fig. S6).

429 After 10 days, we isolated meiotic progeny and examined the frequency of His+ Ura+ recombinant

430 spores derived from both $\left[\mathrm{MPH}^{+}\right]$and $\left[\mathrm{mph1}^{-}\right]$parents. Recombinant phenotypes (i.e. those in which

431 re-assortment of linked parental markers occurred) were substantially more common in meiotic

432 progeny derived from $\left[\mathrm{MPH}^{+}\right]$parents compared to those derived from [ $\left.\mathrm{mph}^{-}\right]$parents $(4.4$-fold; $P=$

4330.02 by T-test; Fig. 5B), establishing that the prion fundamentally altered the degree of linkage the cross.

434 S. cerevisiae naturally produces many crossovers per chromosome, a feature that has motivated

435 its use as a genetic model organism. As a consequence, its linkage blocks are small and most

436 polymorphisms within them are thought to be passenger mutations rather than causal variants. We

437 nonetheless investigated whether $\left[\mathrm{MPH1}^{+}\right]$might spark increased phenotypic variation in natural $\mathrm{S}$.

438 cerevisiae outcrosses. We mated isogenic $[\mathrm{mph1}]$ and $\left[\mathrm{MPH}^{+}\right]$laboratory strains to a sequenced clinical

439 strain isolated from an Italian patient (YJM975 (Strope et al., 2015)). As a frame of reference, the genetic

440 divergence between open reading frames in these strains $(0.5 \%)$ is only slightly greater than that

441 between human individuals. We isolated diploids from these matings, induced meiosis, and isolated

442 spores (Fig. 5C; see SI). We confirmed that these spores were bona fide meiotic recombinants based on 
443 mating type tests and then exposed these progeny to physiological stressors relevant to the clinical

444 niche: heat stress, antifungal drugs, and oxidative stress, measuring colony size as a proxy for growth.

445 The presence of $\left[\mathrm{MPH}^{+}\right]$significantly increased the phenotypic variation in these cells (Fig. 5D-G).

446 To test whether this increased phenotypic diversity arose from the enhanced re-assortment of

447 genetic information during meiosis, or rather due to some other effect of $\left[\mathrm{MPH}^{+}\right]$(e.g. decreased

448 mutation rate, phenotypic capacitance, etc.), we also examined phenotypic variation produced by the

449 prion in the parental strains. We transferred $\left[\mathrm{MPH}^{+}\right]$to each parent by cytoduction (see SI for

450 experimental details) and examined the variance in phenotype across the same stressors that we used

451 to examine the meiotic progeny. The variance in phenotype imparted by $\left[\mathrm{MPH}^{+}\right]$was much smaller in

452 each parent than it was in the meiotic progeny (Fig. 5D-G, Fig. S7) and curing of the prion did not

453 eliminate these traits (Fig. S9), establishing that the prion itself did not increase phenotypic variance in a

454 static genetic background. Thus, even given a restricted degree of parental genetic diversity and the high

455 baseline recombination rate of $S$. cerevisiae, $\left[\mathrm{MPH}^{+}\right]$can sharply increase heritable phenotypic

456 diversification during meiosis.

457 Changes in protein homeostasis have previously been shown to modulate genotype to

458 phenotype relationships (Jarosz et al., 2010). To confirm that $\left[\mathrm{MPH}^{+}\right]$was not acting as a phenotypic

459 capacitor and influencing manifestation of the observed phenotypes in the new genetic backgrounds,

460 we picked multiple meiotic progeny and "cured" them of $\left[\mathrm{MPH}^{+}\right]$via transient inhibition of the

461 molecular chaperone Hsp70 (Chakrabortee et al., 2016). Outlier progeny both resistant and sensitive to

462 heat stress were transformed with a plasmid containing a dominant negative variant of Hsp70 (Ssa1-

$463 \mathrm{~K} 69 \mathrm{M}$ ) and propagated for $\sim 75$ generations on selective media to eliminate inheritance of the prion (as

464 has been described previously). Then the plasmid was eliminated and normal Hsp70 function was

465 restored for an additional $\sim 25$ generations. The strains were then arrayed onto a plate in a 10-fold

466 dilution series and allowed to grow up for 3 days (Fig. S8). While $\left[\mathrm{MPH} 1^{+}\right]$-dependent phenotypes (e.g. 
bioRxiv preprint doi: https://doi.org/10.1101/152512; this version posted June 20,2017 . The copyright holder for this preprint (which was not certified by peer review) is the author/funder. All rights reserved. No reuse allowed without permission.

467 zinc resistance) were curable in this experiment, phenotypes that arose uniquely in the meiotic progeny

468 (e.g. resistance to heat stress) were not.

469

470

471

472 


\section{Discussion}

474 To survive in dynamic, fluctuating environments, organisms must acquire new heritable traits. However,

475 a multitude of mechanisms that safeguard DNA replication often create a phenotypic 'lock in', limiting

476 the source of biological novelty to relatively modest changes in the genetic code. Dynamic,

477 environmentally regulated signaling networks offer one solution to this problem. Epigenetic 'bet-

478 hedging' mechanisms may provide another (Halfmann et al., 2010; Lancaster and Masel, 2009; True and

479 Lindquist, 2000). Such systems increase phenotypic variation, creating sub-populations that express

480 different traits than the majority. In fluctuating environments, these new traits might enable survival of

481 the population when it would otherwise have perished. However, the evolutionary value of most bet-

482 hedging systems, including those driven by prions, depends upon the constant presence of the causal

483 element. Mechanisms of this type have been implicated in the interpretation of genetic information

484 (True and Lindquist, 2000), but none are known to permanently alter the genome. Our data establish

485 that one such element, the prion $\left[\mathrm{MPH}^{+}\right]$, has the power to do so. This prion is highly transmissible and

486 can be induced in environments where it is adaptive, providing a robust mechanism for Lamarckian

487 inheritance that controls fundamental decisions in DNA damage tolerance, mutagenesis, and meiotic

488 recombination.

489 Perhaps the greatest force driving genetic diversification in eukaryotes is sexual reproduction.

490 Re-assortment of alleles in meiosis ensures that every genome is fundamentally new. But within this

491 genomic patchwork, linkage blocks can be found in which multiple polymorphisms are inherited in cis.

492 As an epistemological tool, geneticists have long assumed that individual, 'driver' polymorphisms are

493 linked to many other 'passenger' mutations that have no influence on phenotype. Yet evidence from

494 fine mapping studies of individual quantitative trait loci in S. cerevisiae (Steinmetz et al., 2002) and

495 metazoans (Mackay et al., 2009) alike suggest that multiple causal alleles can often occur within a single

496 linked genetic locus. The increased phenotypic diversity that we observed in genetic crosses with 
$497\left[\mathrm{MPH}^{+}\right]$parents suggest, even in crosses with limited genetic diversity and in an organism with small

498 haplotype blocks, that alleles impacting the same phenotype can commonly be linked. This genetic

499 architecture may allow complex traits to persist in a greater number of meiotic progeny, which provides

500 theoretical adaptive advantages. But it also limits meiotic re-assortment of the linked alleles. The

$501\left[\mathrm{MPH}^{+}\right]$prion provides a molecular mechanism through which this fundamental decision - whether to

502 couple or separate bits of genetic information as they are broadcast to the next generation - can be

503 reset. The phenotypic consequences of such re-assortment, at least in the context of traits relevant to

504 the clinical niche that we tested, are substantially more adaptive than would be expected from random

505 mutagenesis (where $>95 \%$ of mutations are detrimental (Eyre-Walker and Keightley, 2007)).

506 Many prions have long been assumed to be non-functional assemblies of a homogenous

507 protein. However, the fact that the $\left[G A R^{+}\right]$prion is composed of multiple proteins (Jarosz et al., 2014)

508 suggests that some such elements might function as larger complexes. Indeed, the gain-of-function

509 phenotypes driven by $\left[\mathrm{MPH}^{+}\right]$, as well as inheritance from one generation to the next, appear to be

510 dependent on other interacting DNA repair factors (especially those in the yeast FA pathway). Our data

511 also suggest that specific DNA structures may act act as important intermediates for $\left[\mathrm{MPH}^{+}\right]$

512 phenotypes. The linking of diverse physiological outcomes to a single epigenetic state suggests that

$513\left[\mathrm{MPH}^{+}\right]$is a coordinated program that fuels specific and heritable changes in DNA repair networks.

514 During periods of nucleotide starvation, when cells are ill-suited to their environments, they can acquire

$515\left[\mathrm{MPHI}^{+}\right]$at higher rates. This improves their chances of survival and enhances phenotypic diversification

516 of the next generation. Mph1 is not alone in its capacity to assemble in response to replication fork

517 stress (Xue et al., 2014). Many DNA repair factors localize to large assemblies to exert their functions.

518 Our data provide an example in which such an assembly can encode a new set of activities that are

519 heritable over long biological timescales, with the capacity to permanently hardwire adaptive

520 phenotypic diversity into the genome. 


\section{Acknowledgements}

522 This work was supported by a National Institutes of Health New Innovator Award (NIH-DP2-GM119140),

523 an NSF career award (NSFMCB1453762), a Searle Scholar Award (14-SSP-210), a Kimmel Scholar Award

524 (SKF-15-154), and by a Science and Engineering Fellowship from the David and Lucile Packard

525 Foundation to DFJ. JSB was supported by National Institutes of Health Training Grant (5T32GM007790-

526 36). DMG was supported by a postdoctoral fellowship from the NIH (F32-GM109680). We thank

527 members of the Jarosz laboratory as well as K. Cimprich (Stanford) and X. Zhao (MSKCC) for helpful

528 comments, and S. Larios (Stanford) for reagent support.

529

530 Financial Interests Statement

531

532 The authors declare no competing financial interests.

533 
Figure 1. $\left[\mathrm{MPH1}^{+}\right]$is a prion that protects against DNA damage mutagenesis. (A) "Frequency of prion

537 infectivity" for protein transformation comparing [ $\left.\mathrm{mph}^{-}\right]$lysates (Mock) and $\left[\mathrm{MPH}^{+}\right]$-harboring lysates.

538 Infectivity is calculated as described in methods. [ $\left.\mathrm{MPH1}^{+}\right]$was scored by resistance to $\mathrm{ZnSO}_{4}$

539 (Chakrabortee et al., 2016). Infectivity from assembled $\left[\mathrm{PSI}^{+}\right]$is displayed as a dotted horizontal line

540 (Tanaka and Weissman, 2006). (B) Growth of $\left[\mathrm{MPH}^{+}\right]$and $m p h 1 \Delta$ cells in genotoxic stress relative to

541 naïve [mph1'] cells. Error bars represent SEM from three or more biological replicates. (C-D)

542 Spontaneous and induced mutation frequencies of $\left[\mathrm{MPH}^{+}\right]$and $m p h 1 \Delta$ cells, relative to naïve [ $\left.m p h 1^{-}\right]$,

543 after growth in YPD (spontaneous) or after exposure to mutagenic agents (ex. $0.012 \% \mathrm{MMS}$ or $100 \mu \mathrm{M}$

544 oxolinic acid) (see methods for details). Naïve mutation frequencies increased dramatically after

545 exposure to MMS and oxolinic acid $\left(5 \times 10^{-4}\right.$ and $2 \times 10^{-5}$ mutants per CFU respectively). Error bars

546 represent SEM from 3 independent experiments.

548 Figure 2. $\left[\mathrm{MPH}^{+}\right]$requires helicase activity and FA pathway components. (A) Experimental schema for

549 crossing $\left[\mathrm{MPH}^{+}\right]$into mutant strains to determine whether $\left[\mathrm{MPH}^{+}\right]^{\prime}$ 's catalytic activity or interacting

550 proteins are required to manifest prion phenotypes (in haploid progeny) and/or propagate the prion. (B)

551 Haploid parents: growth of wild-type $\left[\mathrm{mph1}^{-}\right]$and $\left[\mathrm{MPH}^{+}\right]$in the DNA damage stressor 4-NQO (1.2 $\left.\mu \mathrm{M}\right)$.

552 Haploid mutant progeny: growth of $\left[\mathrm{mph1}^{-}\right]$and $\left[\mathrm{MPH}^{+}\right]$strains harboring a single catalytically dead

553 point mutation (mph1-Q603D) in the MPH1 gene in $1.2 \mu \mathrm{M}$ 4-NQO. Heterozygous diploids: growth of

$554\left[\mathrm{mph}^{-}\right]$and $\left[\mathrm{MPH}^{+}\right]$catalytically dead mutants in $1.2 \mu \mathrm{M}$ 4-NQO after crossing back to a wild-type

555 strain. Error bars represent SEM determined from 6 biological replicates and are present on all plots. (C)

556 Left $-\Delta$ haploid: heatmap of Log2-transformed fold-changes in growth during DNA damage (4-NQO; see

557 methods) of haploid progeny harboring deletions of Mph1-associated proteins after crossing with an

$558\left[\mathrm{MPH}^{+}\right]$strain. Data are normalized to isogenic $\left[\mathrm{mph1} 1^{-}\right]$controls. $\Delta / \mathrm{WT}$ diploid: data as above, but for 
559 heterozygous diploids in which gene function was restored. Right - representative growth curves of

560 cross-back, heterozygous diploids in which the $\left[\mathrm{MPH}^{+}\right]$phenotype was maintained or restored. Error

561 bars represent SEM determined from 6 biological replicates.

563 Figure 3. Prion-like behavior and intrinsic disorder is conserved in human FANCM. (A) Schematic

564 depicting the toxicity of casual protein overexpression in the presence of the corresponding prion. (B)

565 Growth of $\left[\mathrm{MPH}^{+}\right]$strains harboring plasmids expressing FANCM and Mph1 variants. Values are

566 normalized to corresponding [ $\left.\mathrm{mph}^{-}\right]$strains harboring the same plasmids. Error bars represent SEM

567 from six biological replicates. (C) Scores from an algorithm that predicts prion-like sequences using a

568 Hidden Markov model (PLAAC; (Lancaster et al., 2014)) for both Mph1 and Sup35. (D) Top: Intrinsic

569 disorder predictions (Disopred3; (Jones and Cozzetto, 2015)) for Mph1 and FANCM. Bottom: Variants

570 and domain architecture of Mph1 and FANCM used in this assay.

571

572 Figure 4. $\left[\mathrm{MPH}^{+}\right]$is a quasi-Lamarckian element. (A) Diagram of spontaneous switching from [ $\left.\mathrm{mph}^{-}\right]$

573 to $\left[\mathrm{MPH}^{+}\right]$. In this experiment, naïve reporter cells were treated with indicated stressors for 12 hours

574 and assayed for modulated switching frequencies to $\left[\mathrm{MPH}^{+}\right]$. (B) Induction of $\left[\mathrm{MPH}^{+}\right]$compared to

575 control in various conditions. Error bars represent SEM from 3 biological replicates. (C) $\left[\mathrm{MPH} 1^{+}\right]-$

576 dependent changes in mutation frequency following a transient PIF1 overexpression to eliminate G-

577 quadruplex regions (Paeschke et al., 2013) and subsequent recovery after $\sim 70$ generations in rich media.

578 Values normalized to corresponding [ $\left.\mathrm{mph1}^{-}\right]$strain. Error bars represent SEM from 8 biological 579 replicates.

580

581 Figure 5. $\left[\mathrm{MPH}^{+}\right]$increases phenotypic diversification in the progeny of meiosis. (A) Experimental 582 schema for measuring linkage between 2 auxotrophic markers in $\left[\mathrm{mph} 1^{-}\right]$and $\left[\mathrm{MPH1}^{+}\right]$strains. (B) 
583 Relative frequencies of His+ Ura+ meiotic recombinant progeny in [ $\left.m p h 1^{-}\right],\left[\mathrm{MPH}^{+}\right], m p h 1 \Delta$ strains

584 compared to [mph1]]. Error bars represent SEM from 4 biological replicates. (C) Experimental schema for

585 determining $\left[\mathrm{MPH}^{+}\right]$-dependent phenotypic diversification following a cross between lab strains (with

586 or without $\left.\left[\mathrm{MPH}^{+}\right]\right)$and a recently evolved clinical pathogen. (D-G) Histograms of normalized spore

587 colony sizes from these crosses (calculated using SGAtools (Wagih et al., 2013)) in 4 clinically relevant

588 stressors. Histograms were fit to a Gaussian distribution to generate curves.

590 Supplemental Figure 1. Localization of $\mathrm{Mph1}$ protein in $\left[\mathrm{MPH1}^{+}\right]$cells. Fluorescence micrographs from

591 diploid cells harboring $\left[\mathrm{MPH1}^{+}\right]$, or [mph1'] control, each expressing integrated MPH1-YFP from its

592 endogenous promoter. Exponential phased cells were imaged at $\mathrm{OD}_{600} \sim 0.5-0.8$, stationary phase at

$593 \mathrm{OD}_{600} \sim 1.5-2$.

594

595 Supplemental Figure 2. $\left[\mathrm{MPH}^{+}\right]$is a cytoplasmic element. (A). Experimental schema of cytoduction

596 experiments. (B) Growth of $\left[\mathrm{mph1}^{-}\right]$and $\left[\mathrm{MPH}^{+}\right]$cytoduced strains in a DNA stressor to which $\left[\mathrm{MPH1}^{+}\right]$

597 promotes resistance (10 $\mu \mathrm{M}$ mycophenolic acid). Error bars represent SEM from 3 biological replicates.

598 (C) Experimental schema for protein transformation experiments.

600 Supplemental Figure 3. $\left[\mathrm{MPH}^{+}\right]$does not influence GCR mutagenesis. (A) Diagram of GCR reporter

601 used. Two counter-selectable markers (URA3 and CAN1) are located upstream of an essential gene

602 (PCM1). When cells are presented with a double counter-selection, the probability of mutating both

603 genes in a single generation is vanishingly small. Therefore, resistant colonies will undergo a GCR event

604 at the precise location, preserving the essential gene. (B) GCR frequencies in [mph1'] and [MPH1 $\left.{ }^{+}\right]$

605 strains. Error bars represent SEM from 5 biological replicates.

606 
607 Supplemental Figure 4. $\left[\mathrm{MPH}^{+}\right]$increases homologous recombination. Normalized genomic 608 integration frequencies of a linear DNA cassette in $[\mathrm{mph1}]$ and $\left[\mathrm{MPH1}^{+}\right]$strains. Error bars represent 609 SEM for 6 biological replicates.

611 Supplemental Figure 5. Expression levels of FANCM and Mph1 variants. Bar graph showing the relative 612 expression levels of FANCM and Mph1 plasmids in $\left[\mathrm{MPH}^{+}\right]$vs. [mph1] strains measured using RT-PCR. 613 Error bars represent SEM from 3 biological replicates.

615 Supplemental Figure 6. $\left[\mathrm{MPH1}^{+}\right]$does not affect sporulation. Fraction of tetrads in $\left[\mathrm{mph1}^{-}\right]$and $616\left[\mathrm{MPH}^{+}\right]$strains after 5 days. Error bars represent SEM from 3 biological replicates.

618 Supplemental Figure 7. Phenotypic variation in $\left[\mathrm{mph1}^{-}\right]$and $\left[\mathrm{MPH}^{+}\right]$derivatives of laboratory and

619 clinical parent strains. Phenotypic distributions of $\left[\mathrm{mph1}^{-}\right]$or $\left[\mathrm{MPH1}^{+}\right]$parental strains for wild cross in 620 the 4 different stressors. Range of $x$-axis used is identical to each corresponding progeny histogram in 621 Figure 5.

623 Supplemental Figure 8. Mph1 does not act as a phenotypic capacitor. Top panel: $\left[\mathrm{MPH1}^{+}\right]$parent strain 624 before and after prion 'curing' spotted in a 10-fold dilution series on a plate containing $10 \mathrm{mM} \mathrm{ZnSO}_{4}$.

625 Bottom panel: Heat-resistant progeny from wild outcross with an $\left[\mathrm{MPH}^{+}\right]$parent before and after prion 626 'curing' spotted in a 10 -fold dilution series on a YPD plate grown at $39^{\circ} \mathrm{C}$.

628 Supplemental Table 1. Yeast strains used in this study. 
632 Supplemental Table 3. Interacting proteins required for $\left[\mathrm{MPH1}^{+}\right]$-dependent anti-mutator phenotypes.

633 Table showing $\left[\mathrm{mph}^{-}\right]$and $\left[\mathrm{MPH}^{+}\right]$mutation frequencies for haploid progeny harboring genetic

634 knockouts of DNA repair factors. $1^{\text {st }}$ column - genotypes of each strain assayed; $2^{\text {nd }}$ column - mutation

635 frequency with SEM for each knockout in a naïve [mph1] $]$ strain; $3^{\text {rd }}$ column - mutation frequency with

636 SEM for corresponding $\left[\mathrm{MPHI}^{+}\right]$strain; $4^{\text {th }}$ column - Fold-change in mutation frequency by each genetic

637 knockout compared to a wild-type naïve [mph1] strain; $5^{\text {th }}$ column - Fold-change in mutation frequency

638 imparted by $\left[\mathrm{MPH1}^{+}\right]$for the same genotype.

640 REFERENCES

641 Alter, B.P. (1996). Fanconi's anemia and malignancies. Am J Hematol 53, 99-110.

642 Audas, T.E., Audas, D.E., Jacob, M.D., Ho, J.J., Khacho, M., Wang, M., Perera, J.K., Gardiner, C., Bennett,

643 C.A., Head, T., et al. (2016). Adaptation to Stressors by Systemic Protein Amyloidogenesis. Dev Cell 39,

$644 \quad 155-168$.

645 Banerjee, S., Smith, S., Oum, J.H., Liaw, H.J., Hwang, J.Y., Sikdar, N., Motegi, A., Lee, S.E., and Myung, K.

646 (2008). Mph1p promotes gross chromosomal rearrangement through partial inhibition of homologous

647 recombination. J Cell Biol 181, 1083-1093.

648 Cerami, E., Gao, J., Dogrusoz, U., Gross, B.E., Sumer, S.O., Aksoy, B.A., Jacobsen, A., Byrne, C.J., Heuer,

649 M.L., Larsson, E., et al. (2012). The cBio cancer genomics portal: an open platform for exploring

650 multidimensional cancer genomics data. Cancer Discov 2, 401-404.

651 Chakrabortee, S., Byers, J.S., Jones, S., Garcia, D.M., Bhullar, B., Chang, A., She, R., Lee, L., Fremin, B.,

652 Lindquist, S., et al. (2016). Intrinsically Disordered Proteins Drive Emergence and Inheritance of

653 Biological Traits. Cell 167, 369-381 e312. 
654 Chen, Y.H., Choi, K., Szakal, B., Arenz, J., Duan, X., Ye, H., Branzei, D., and Zhao, X. (2009). Interplay

655 between the Smc5/6 complex and the Mph1 helicase in recombinational repair. Proc Natl Acad Sci U S A $656106,21252-21257$.

657 Crismani, W., Girard, C., Froger, N., Pradillo, M., Santos, J.L., Chelysheva, L., Copenhaver, G.P., Horlow,

658 C., and Mercier, R. (2012). FANCM limits meiotic crossovers. Science 336, 1588-1590.

659 Daee, D.L., Ferrari, E., Longerich, S., Zheng, X.F., Xue, X., Branzei, D., Sung, P., and Myung, K. (2012).

660 Rad5-dependent DNA repair functions of the Saccharomyces cerevisiae FANCM protein homolog Mph1.

661 J Biol Chem 287, 26563-26575.

662 Derkatch, I.L., Bradley, M.E., Hong, J.Y., and Liebman, S.W. (2001). Prions affect the appearance of other 663 prions: the story of [PIN(+)]. Cell 106, 171-182.

664 Douglas, P.M., Treusch, S., Ren, H.Y., Halfmann, R., Duennwald, M.L., Lindquist, S., and Cyr, D.M. (2008).

665 Chaperone-dependent amyloid assembly protects cells from prion toxicity. Proc Natl Acad Sci U S A 105, $6667206-7211$.

667 Eyre-Walker, A., and Keightley, P.D. (2007). The distribution of fitness effects of new mutations. Nat Rev 668 Genet 8, 610-618.

669 Farmer, S., San-Segundo, P.A., and Aragon, L. (2011). The Smc5-Smc6 complex is required to remove 670 chromosome junctions in meiosis. PloS one 6, e20948.

671 Fricke, W.M., and Brill, S.J. (2003). Slx1-SIx4 is a second structure-specific endonuclease functionally 672 redundant with Sgs1-Top3. Genes Dev 17, 1768-1778.

673 Gietz, D., St Jean, A., Woods, R.A., and Schiestl, R.H. (1992). Improved method for high efficiency

674 transformation of intact yeast cells. Nucleic Acids Res 20, 1425.

675 Halfmann, R., Alberti, S., and Lindquist, S. (2010). Prions, protein homeostasis, and phenotypic diversity. 676 Trends Cell Biol 20, 125-133. 
677 Holmes, D.L., Lancaster, A.K., Lindquist, S., and Halfmann, R. (2013). Heritable remodeling of yeast 678 multicellularity by an environmentally responsive prion. Cell 153, 153-165.

679 Huang, J., Liu, S., Bellani, M.A., Thazhathveetil, A.K., Ling, C., de Winter, J.P., Wang, Y., Wang, W., and 680 Seidman, M.M. (2013). The DNA translocase FANCM/MHF promotes replication traverse of DNA 681 interstrand crosslinks. Mol Cell 52, 434-446.

682 Jarosz, D.F., Brown, J.C., Walker, G.A., Datta, M.S., Ung, W.L., Lancaster, A.K., Rotem, A., Chang, A., 683 Newby, G.A., Weitz, D.A., et al. (2014). Cross-kingdom chemical communication drives a heritable, 684 mutually beneficial prion-based transformation of metabolism. Cell 158, 1083-1093.

685 Jarosz, D.F., Taipale, M., and Lindquist, S. (2010). Protein homeostasis and the phenotypic manifestation 686 of genetic diversity: principles and mechanisms. Annu Rev Genet 44, 189-216.

687 Jones, D.T., and Cozzetto, D. (2015). DISOPRED3: precise disordered region predictions with annotated 688 protein-binding activity. Bioinformatics 31, 857-863.

689 Kulak, N.A., Pichler, G., Paron, I., Nagaraj, N., and Mann, M. (2014). Minimal, encapsulated proteomic690 sample processing applied to copy-number estimation in eukaryotic cells. Nat Methods 11, 319-324.

691 Lancaster, A.K., and Masel, J. (2009). The evolution of reversible switches in the presence of irreversible 692 mimics. Evolution 63, 2350-2362.

693 Lancaster, A.K., Nutter-Upham, A., Lindquist, S., and King, O.D. (2014). PLAAC: a web and command-line 694 application to identify proteins with prion-like amino acid composition. Bioinformatics 30, 2501-2502.

695 Lorenz, A., Osman, F., Sun, W., Nandi, S., Steinacher, R., and Whitby, M.C. (2012). The fission yeast 696 FANCM ortholog directs non-crossover recombination during meiosis. Science 336, 1585-1588.

697 Mackay, T.F., Stone, E.A., and Ayroles, J.F. (2009). The genetics of quantitative traits: challenges and 698 prospects. Nat Rev Genet 10, 565-577.

699 McMahill, M.S., Sham, C.W., and Bishop, D.K. (2007). Synthesis-dependent strand annealing in meiosis. $700 \quad$ PLoS Biol 5, e299. 
701 Meetei, A.R., Sechi, S., Wallisch, M., Yang, D., Young, M.K., Joenje, H., Hoatlin, M.E., and Wang, W.

702 (2003). A multiprotein nuclear complex connects Fanconi anemia and Bloom syndrome. Mol Cell Biol 23,

$703 \quad 3417-3426$.

704 Moldovan, G.L., and D'Andrea, A.D. (2009). How the fanconi anemia pathway guards the genome. Annu

705 Rev Genet 43, 223-249.

706 Paeschke, K., Bochman, M.L., Garcia, P.D., Cejka, P., Friedman, K.L., Kowalczykowski, S.C., and Zakian,

707 V.A. (2013). Pif1 family helicases suppress genome instability at G-quadruplex motifs. Nature $497,458-$

708462.

709 Rockmill, B., Lambie, E.J., and Roeder, G.S. (1991). Spore enrichment. Methods in Enzymology 194, 146-

710149.

711 Scheller, J., Schurer, A., Rudolph, C., Hettwer, S., and Kramer, W. (2000). MPH1, a yeast gene encoding a

712 DEAH protein, plays a role in protection of the genome from spontaneous and chemically induced

713 damage. Genetics 155, 1069-1081.

714 Shorter, J., and Lindquist, S. (2005). Prions as adaptive conduits of memory and inheritance. Nat Rev

715 Genet 6, 435-450.

716 Soustelle, C., Vedel, M., Kolodner, R., and Nicolas, A. (2002). Replication protein A is required for meiotic

717 recombination in Saccharomyces cerevisiae. Genetics 161, 535-547.

718 Steinmetz, L.M., Sinha, H., Richards, D.R., Spiegelman, J.I., Oefner, P.J., McCusker, J.H., and Davis, R.W.

719 (2002). Dissecting the architecture of a quantitative trait locus in yeast. Nature 416, 326-330.

720 Strope, P.K., Skelly, D.A., Kozmin, S.G., Mahadevan, G., Stone, E.A., Magwene, P.M., Dietrich, F.S., and

721 McCusker, J.H. (2015). The 100-genomes strains, an S. cerevisiae resource that illuminates its natural

722 phenotypic and genotypic variation and emergence as an opportunistic pathogen. Genome Res 25 , 762-

723774. 
724 Suzuki, G., Shimazu, N., and Tanaka, M. (2012). A yeast prion, Mod5, promotes acquired drug resistance

725 and cell survival under environmental stress. Science 336, 355-359.

726 Tanaka, M., and Weissman, J.S. (2006). An efficient protein transformation protocol for introducing

727 prions into yeast. Methods Enzymol 412, 185-200.

728 True, H.L., and Lindquist, S.L. (2000). A yeast prion provides a mechanism for genetic variation and

729 phenotypic diversity. Nature 407, 477-483.

730 Wagih, O., Usaj, M., Baryshnikova, A., VanderSluis, B., Kuzmin, E., Costanzo, M., Myers, C.L., Andrews,

731 B.J., Boone, C.M., and Parts, L. (2013). SGAtools: one-stop analysis and visualization of array-based

732 genetic interaction screens. Nucleic Acids Res 41, W591-596.

733 Ward, T.A., Dudasova, Z., Sarkar, S., Bhide, M.R., Vlasakova, D., Chovanec, M., and McHugh, P.J. (2012).

734 Components of a Fanconi-like pathway control Pso2-independent DNA interstrand crosslink repair in

735 yeast. PLoS genetics 8, e1002884.

736 Whitby, M.C. (2010). The FANCM family of DNA helicases/translocases. DNA Repair (Amst) 9, 224-236.

737 Wickner, R.B., Edskes, H.K., and Shewmaker, F. (2006). How to find a prion: [URE3], [PSI+] and [beta].

738 Methods 39, 3-8.

739 Xue, X., Choi, K., Bonner, J., Chiba, T., Kwon, Y., Xu, Y., Sanchez, H., Wyman, C., Niu, H., Zhao, X., et al.

740 (2014). Restriction of replication fork regression activities by a conserved SMC complex. Molecular cell

$74156,436-445$.

742 Xue, X., Choi, K., Bonner, J.N., Szakal, B., Chen, Y.H., Papusha, A., Saro, D., Niu, H., Ira, G., Branzei, D., et

743 al. (2015a). Selective modulation of the functions of a conserved DNA motor by a histone fold complex.

744 Genes Dev 29, 1000-1005.

745 Xue, X., Sung, P., and Zhao, X. (2015b). Functions and regulation of the multitasking FANCM family of

746 DNA motor proteins. Genes Dev 29, 1777-1788. 
bioRxiv preprint doi: https://doi.org/10.1101/152512; this version posted June 20,2017 . The copyright holder for this preprint (which was not certified by peer review) is the author/funder. All rights reserved. No reuse allowed without permission.

747 Young, C.W., Schochetman, G., and Karnofsky, D.A. (1967). Hydroxyurea-induced inhibition of

748 deoxyribonucleotide synthesis: studies in intact cells. Cancer Res 27, 526-534.

749 


\section{Figure 1}

A

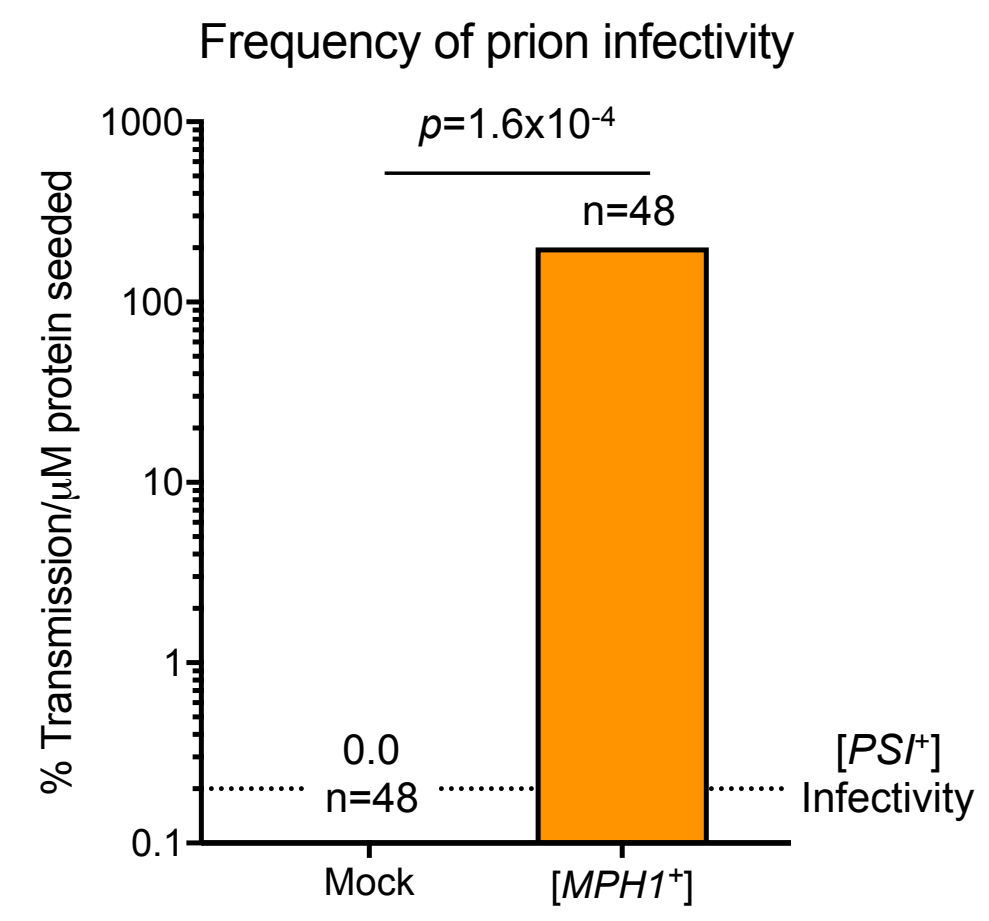

C

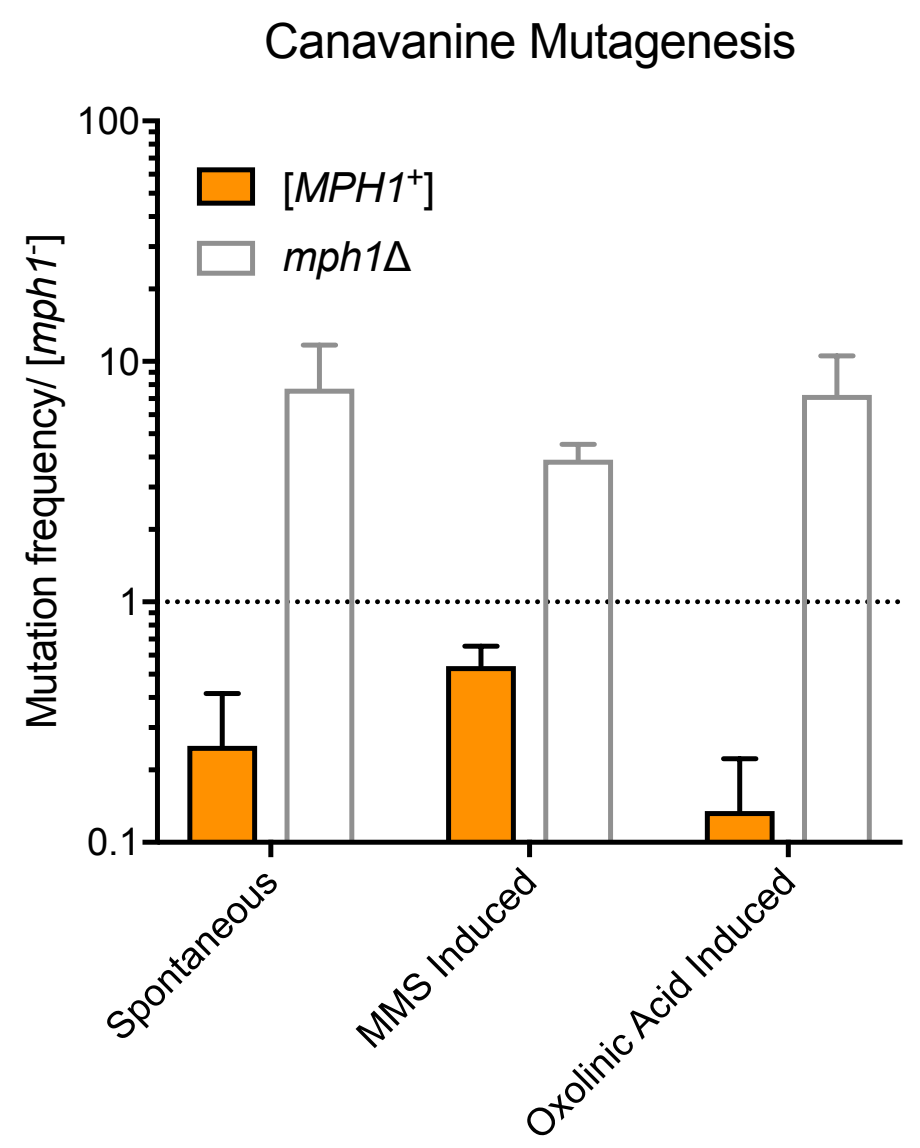

B

Growth in Genotoxic Stressors

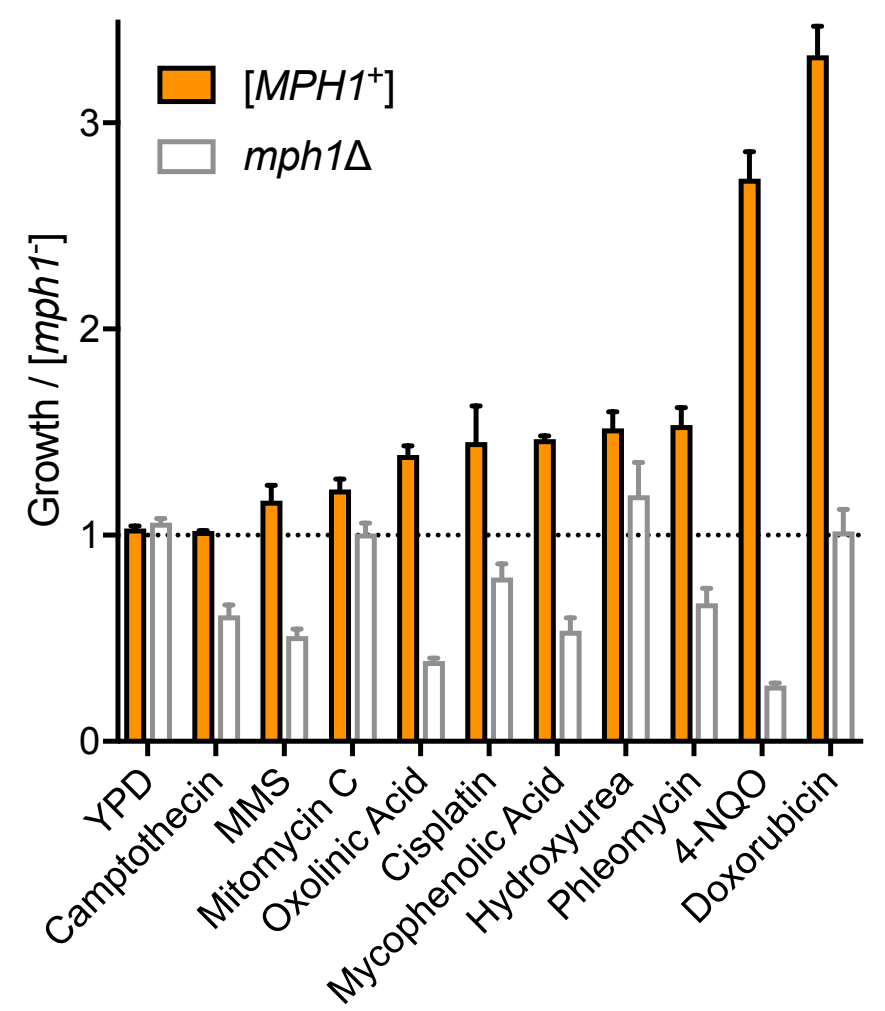

D

Fluconazole mutagenesis

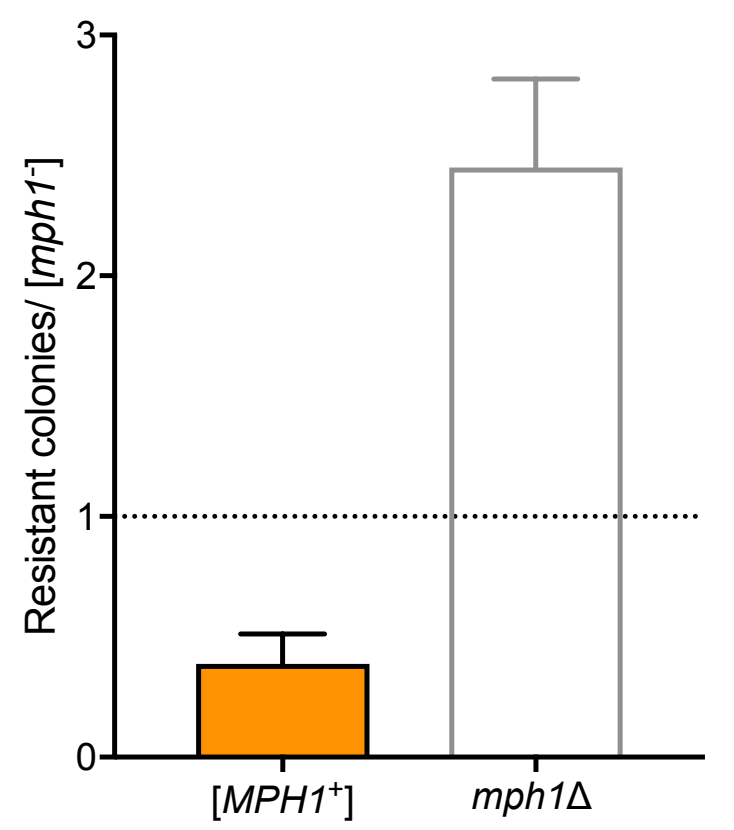




\section{Figure 2}

A

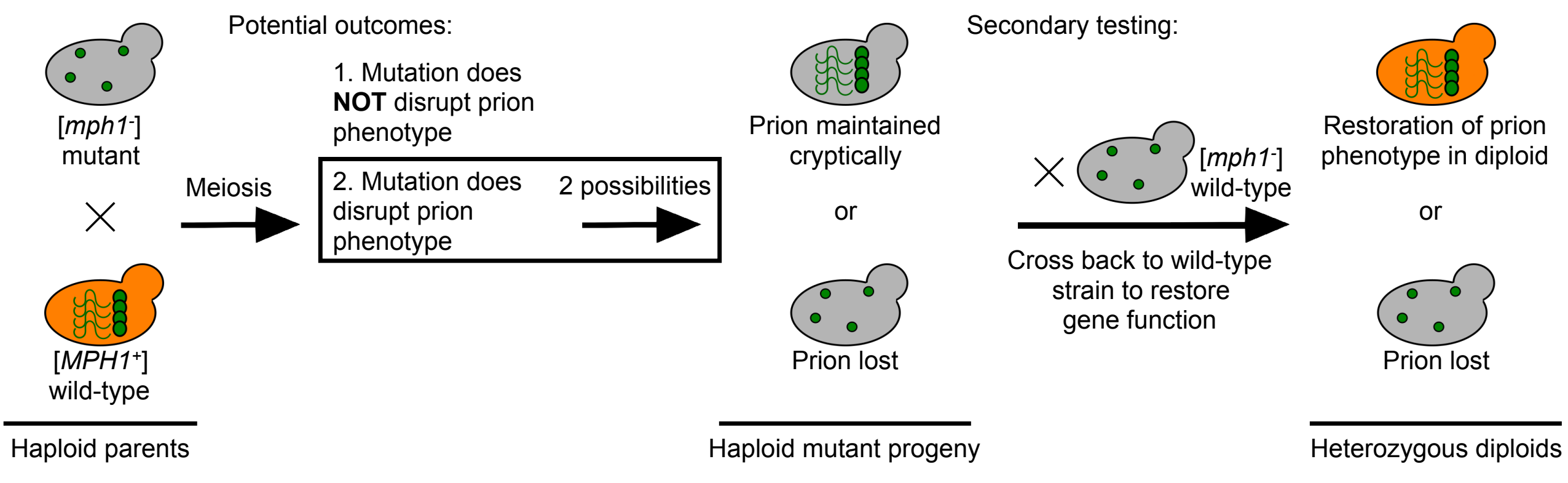

B

$\left[\mathrm{MPH}^{+}\right]$catalytic requirement

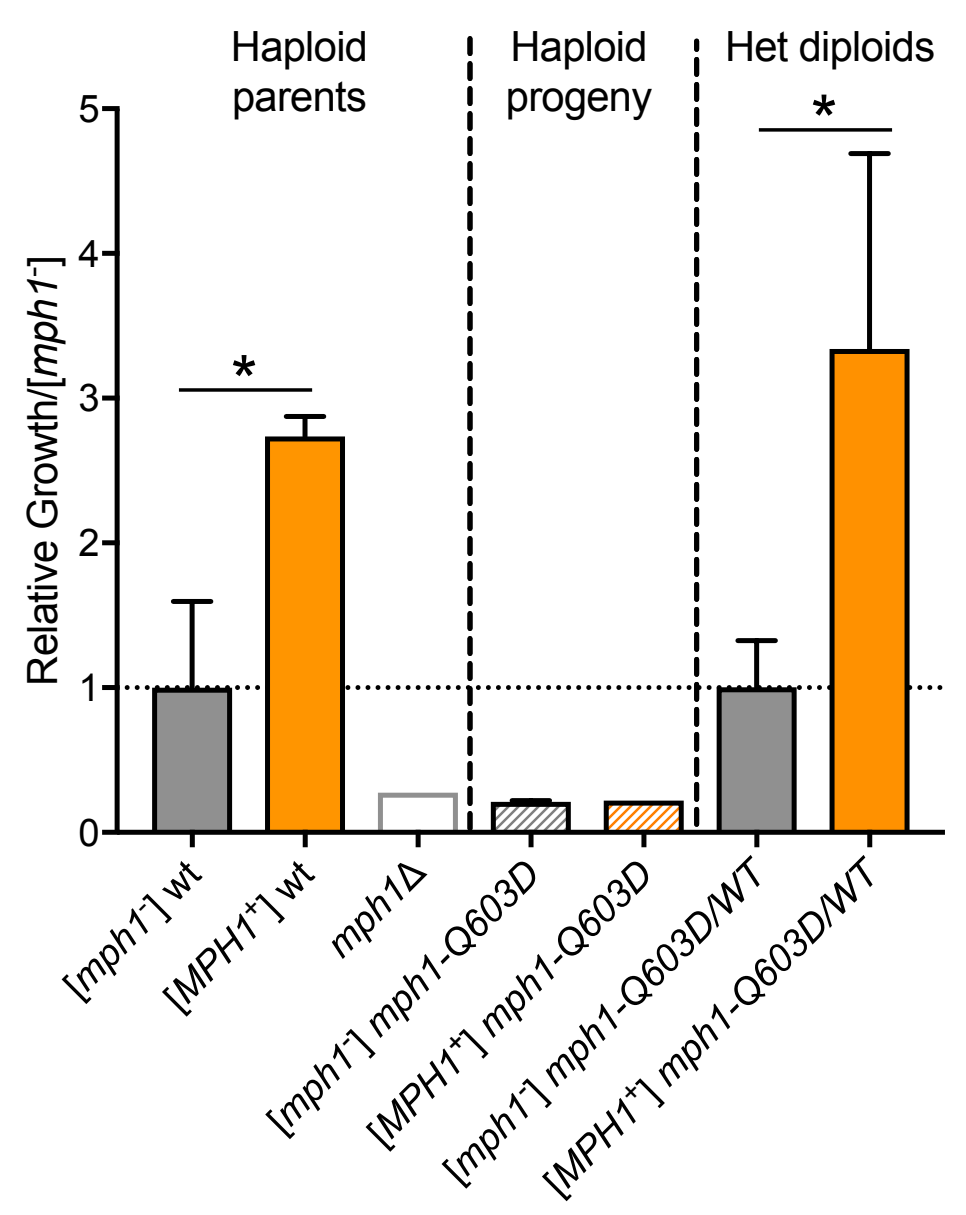

C

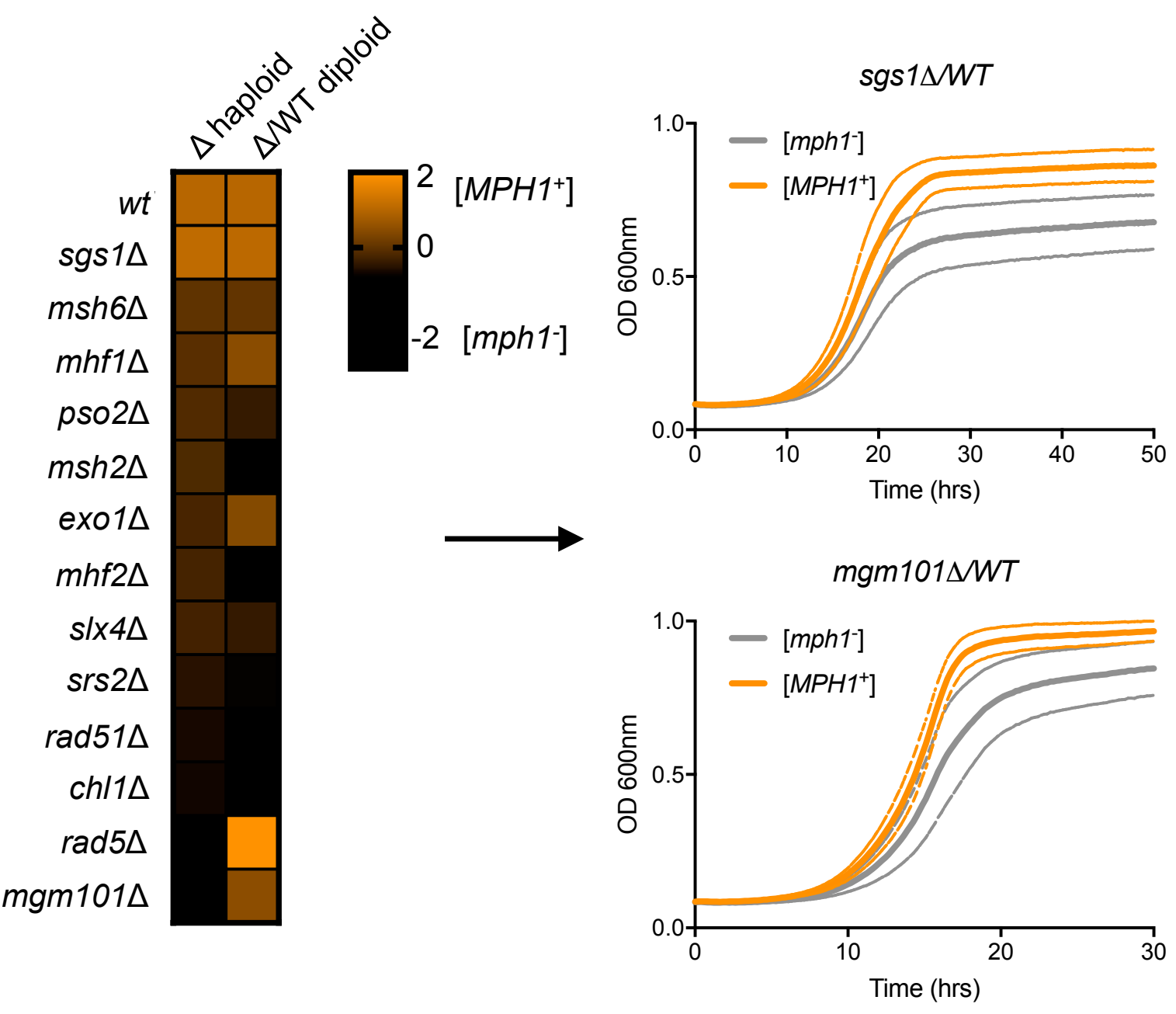




\section{Figure 3}

A

[prion-] cells

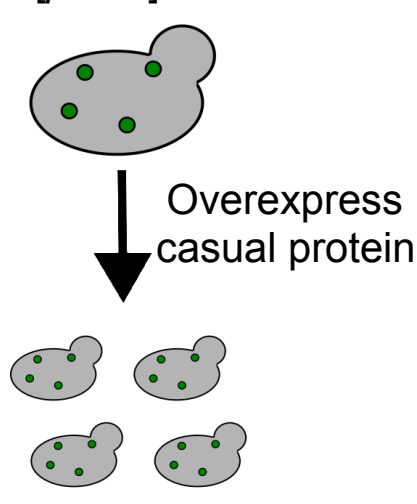

Normal growth
B

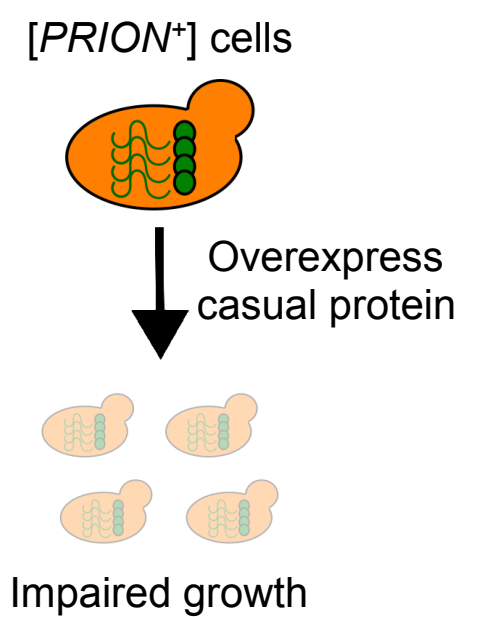

D

Mph1 Disorder Probability

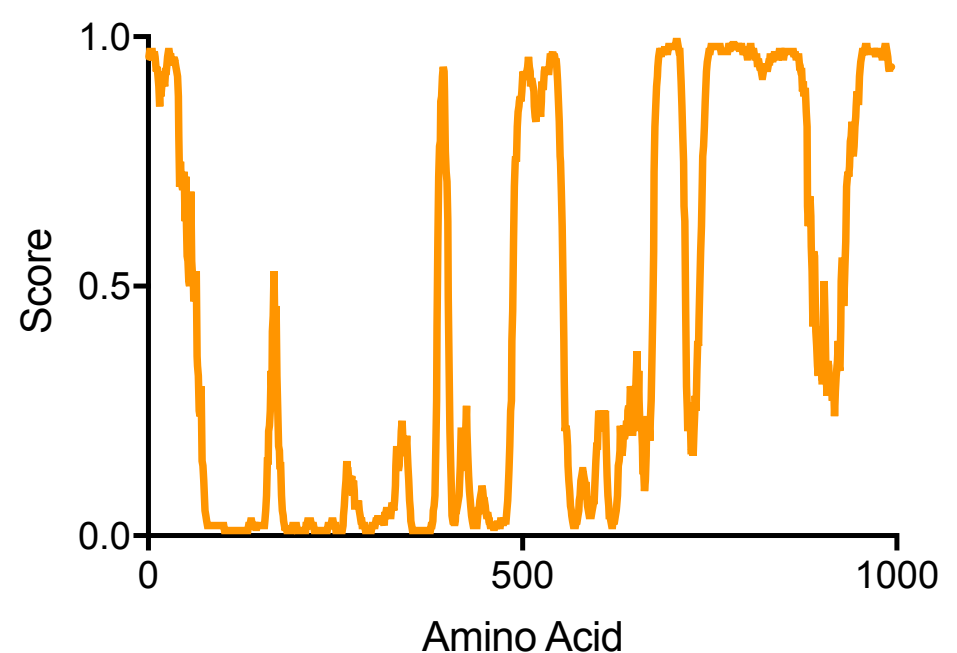

Variants:

ScMph

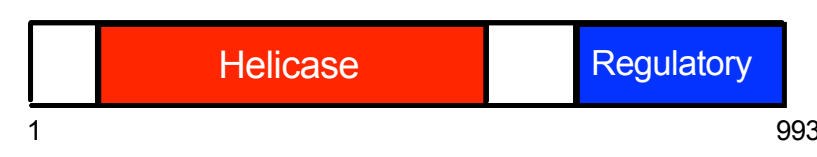

Helicase

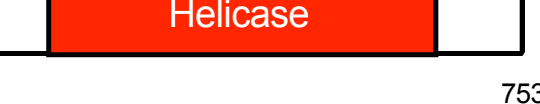

Prion-dependent toxicity of overexpression

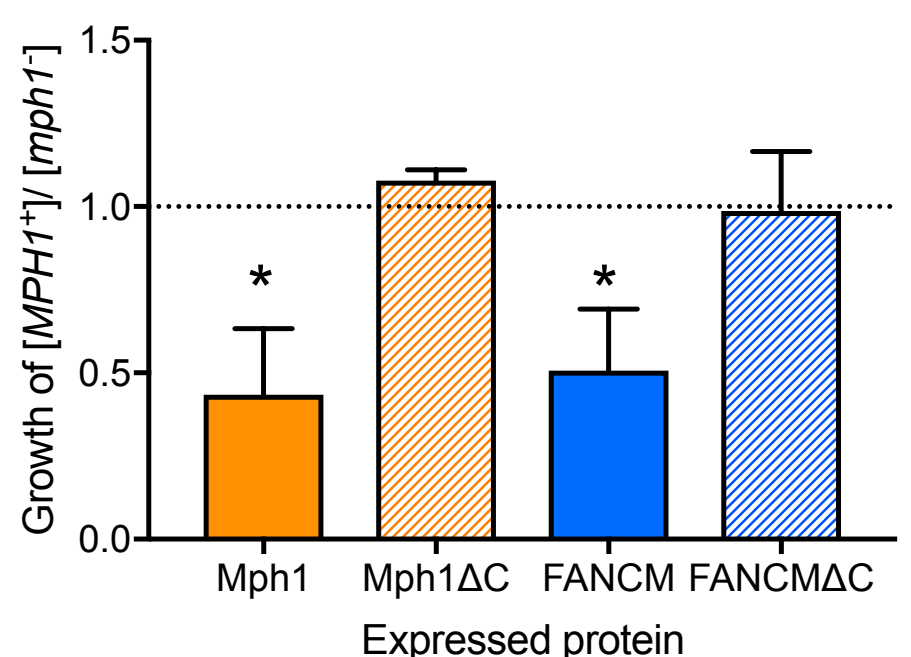

C

Prion Sequence Score

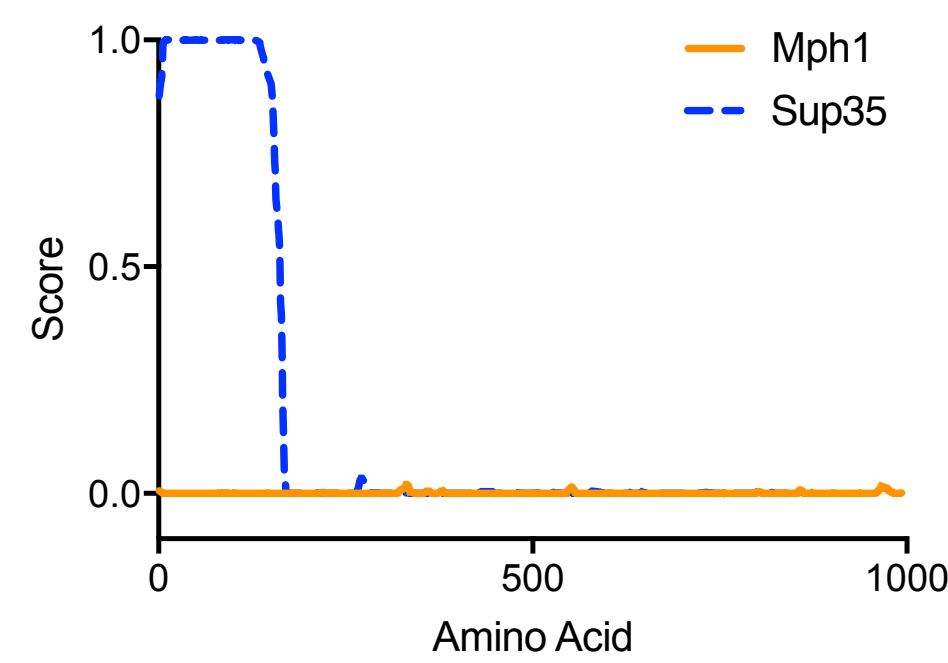

FANCM Disorder Probability

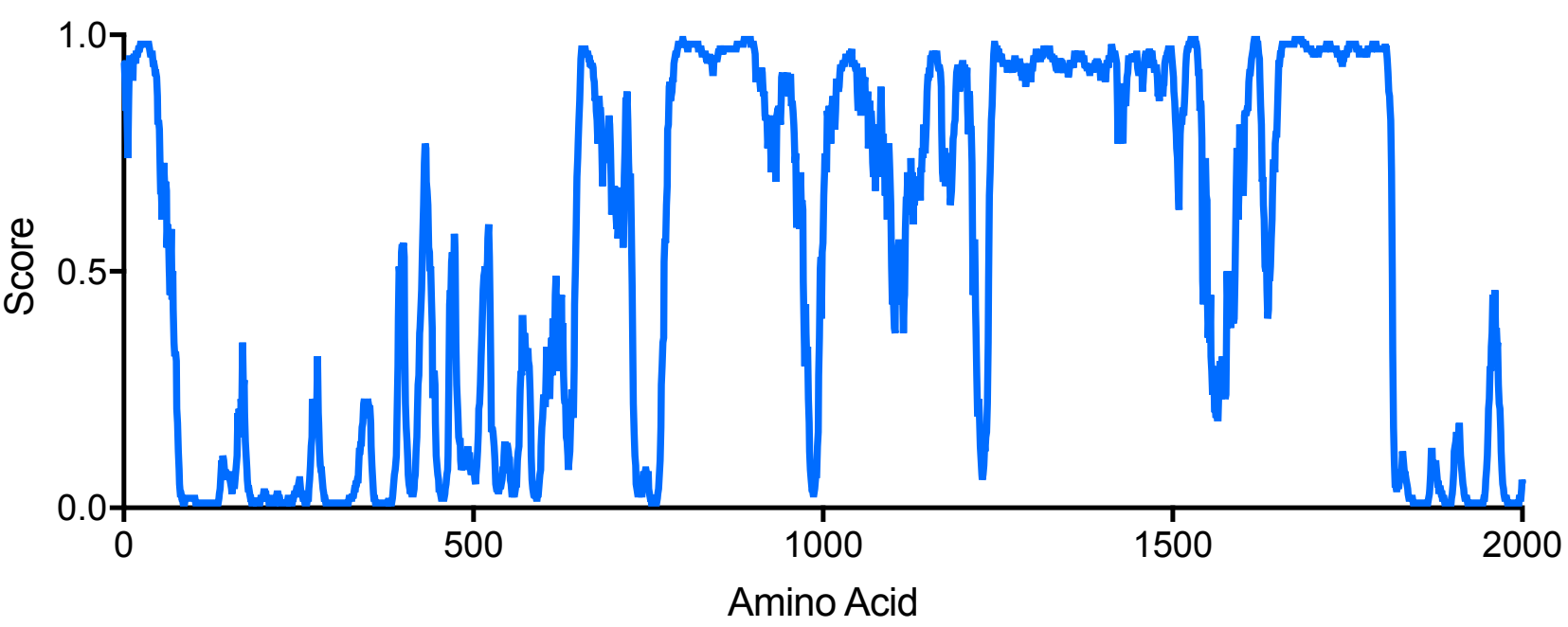

Variants:

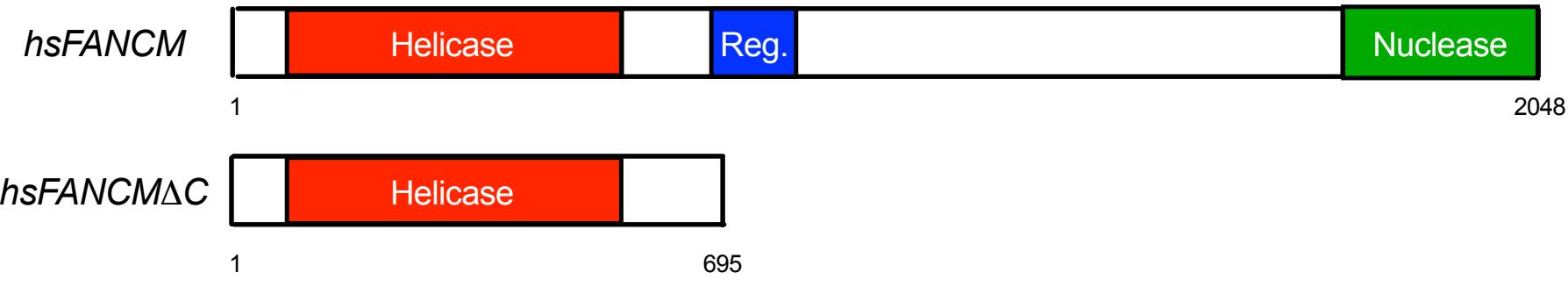




\section{Figure 4}

A

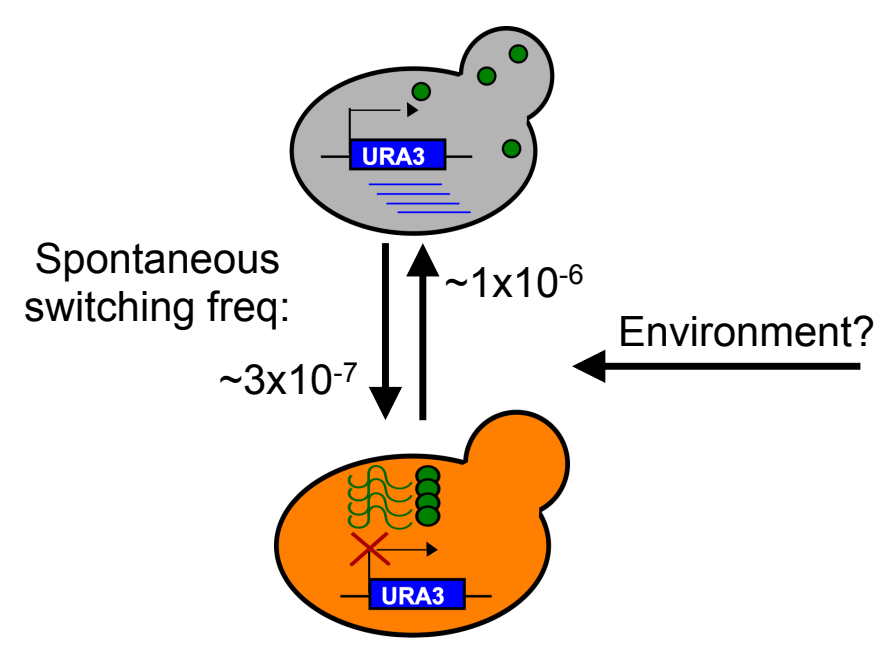

B

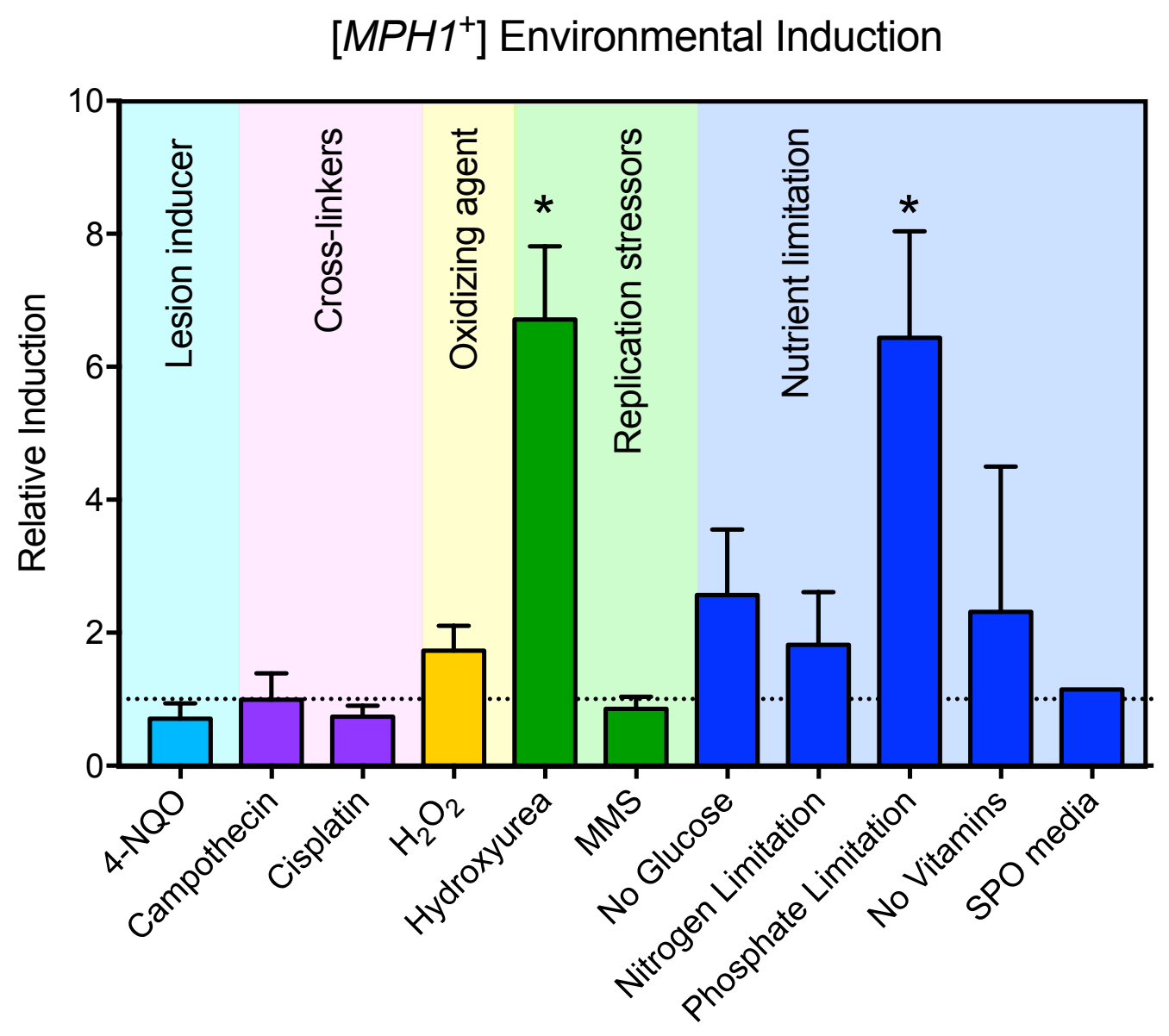

C

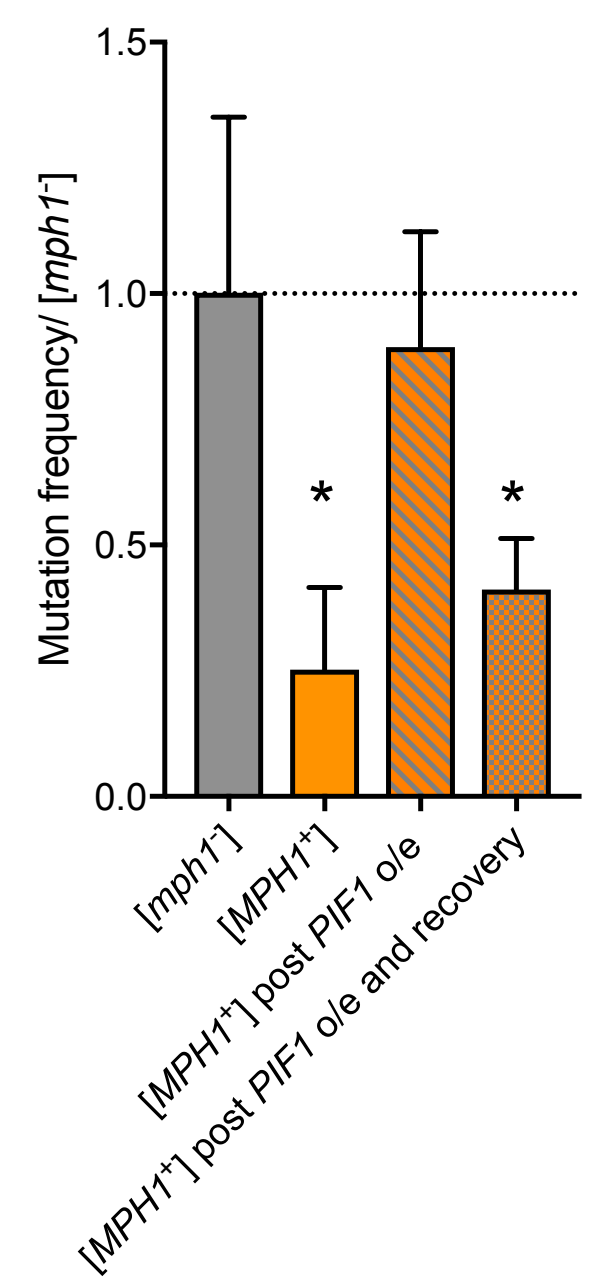




\section{Figure 5}

A

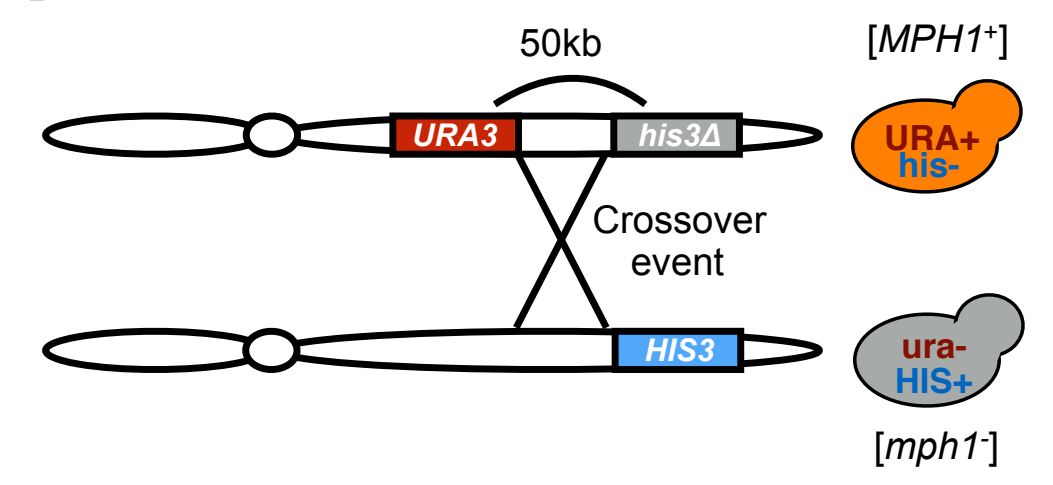

C

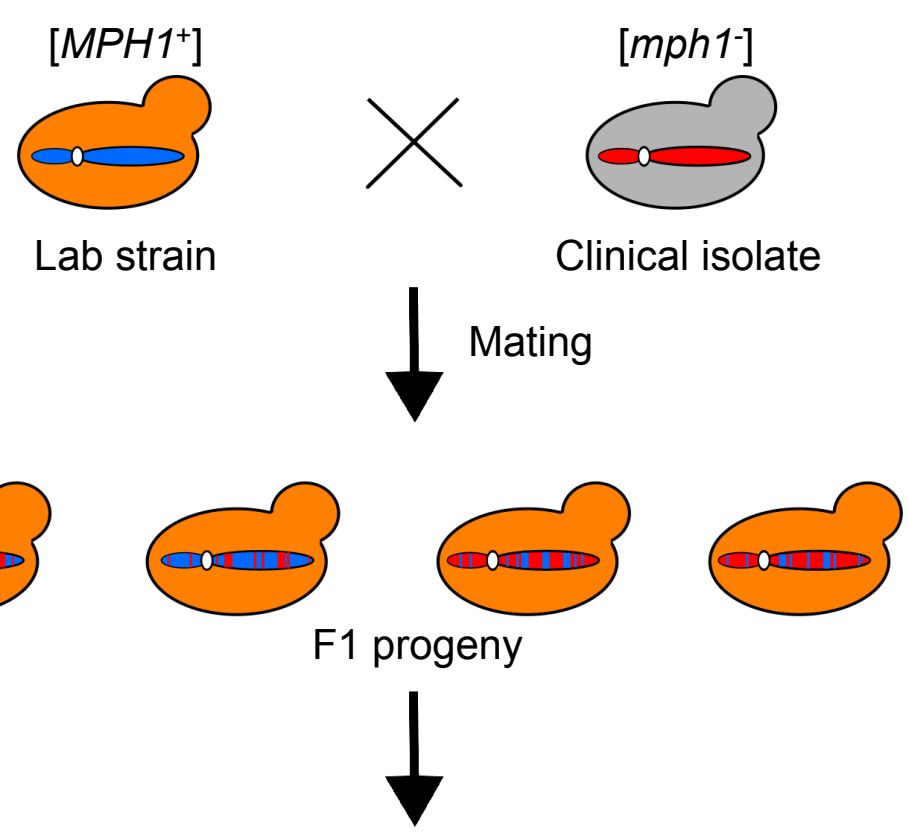

Battery of stressors

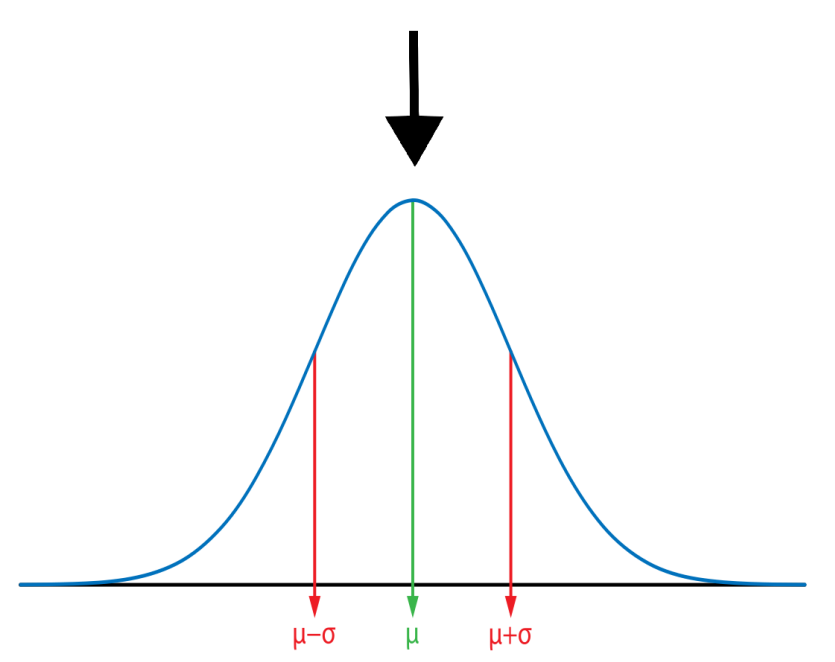

Phenotypic distribution

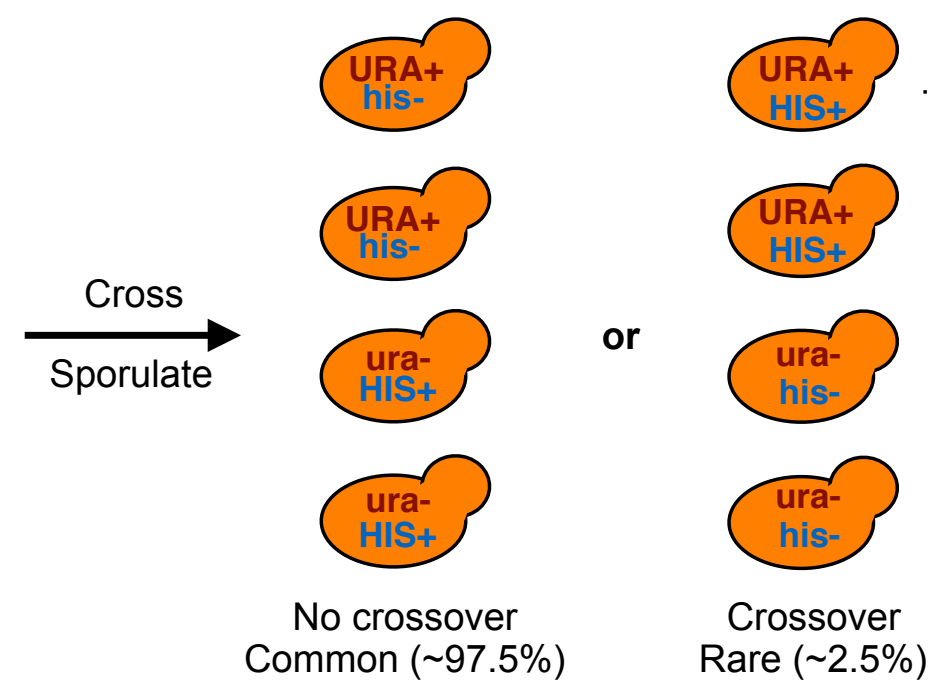

D

$39^{\circ} \mathrm{C}$ Heat Stress

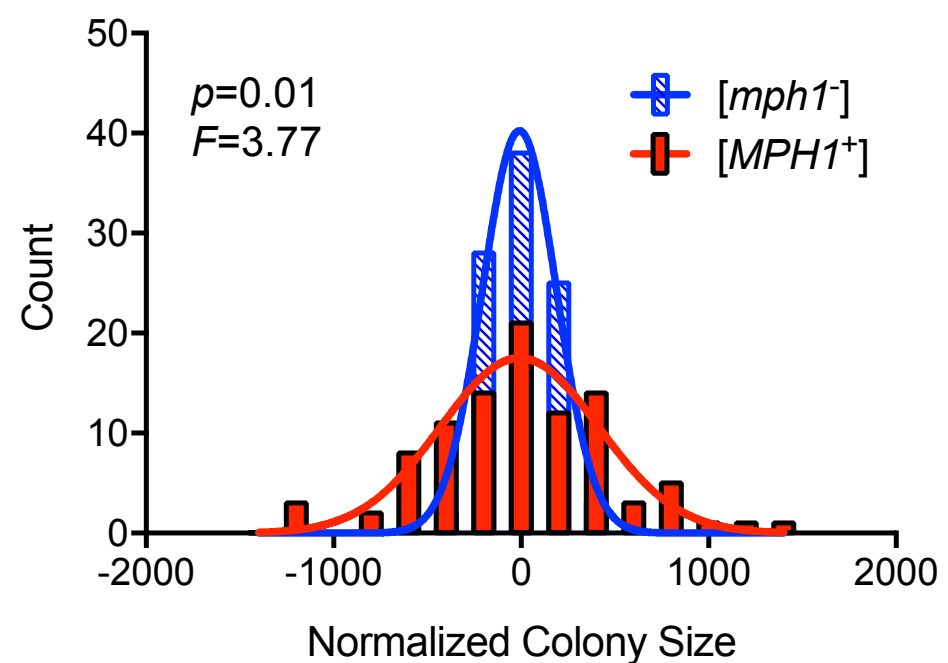

F

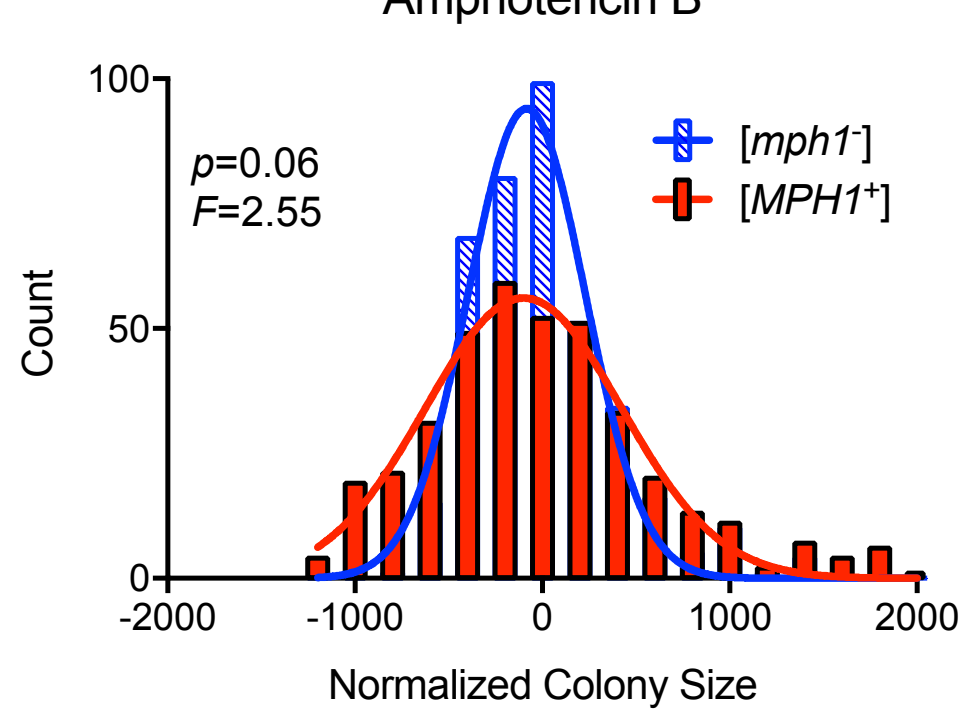

B

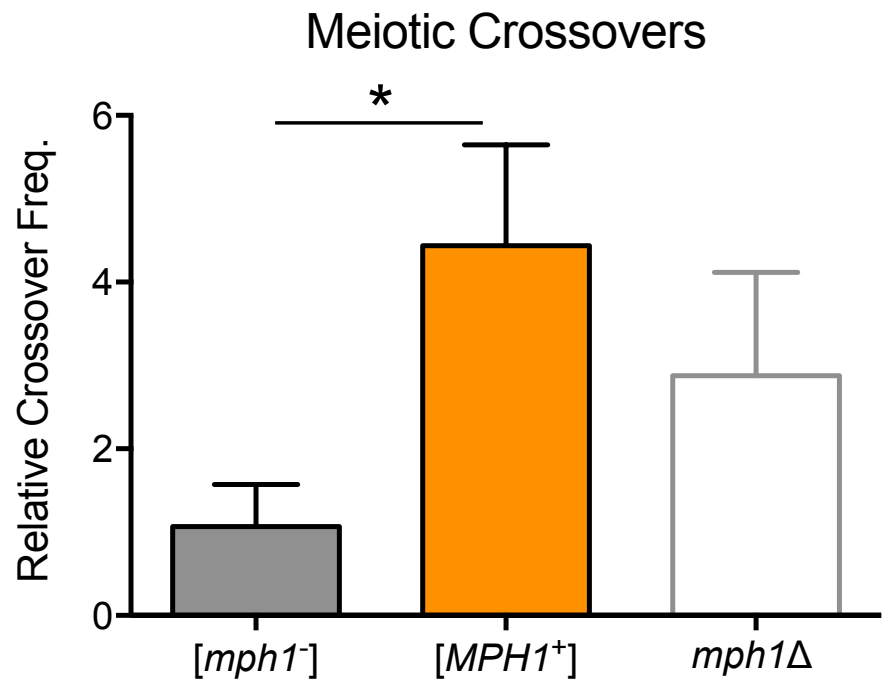

E

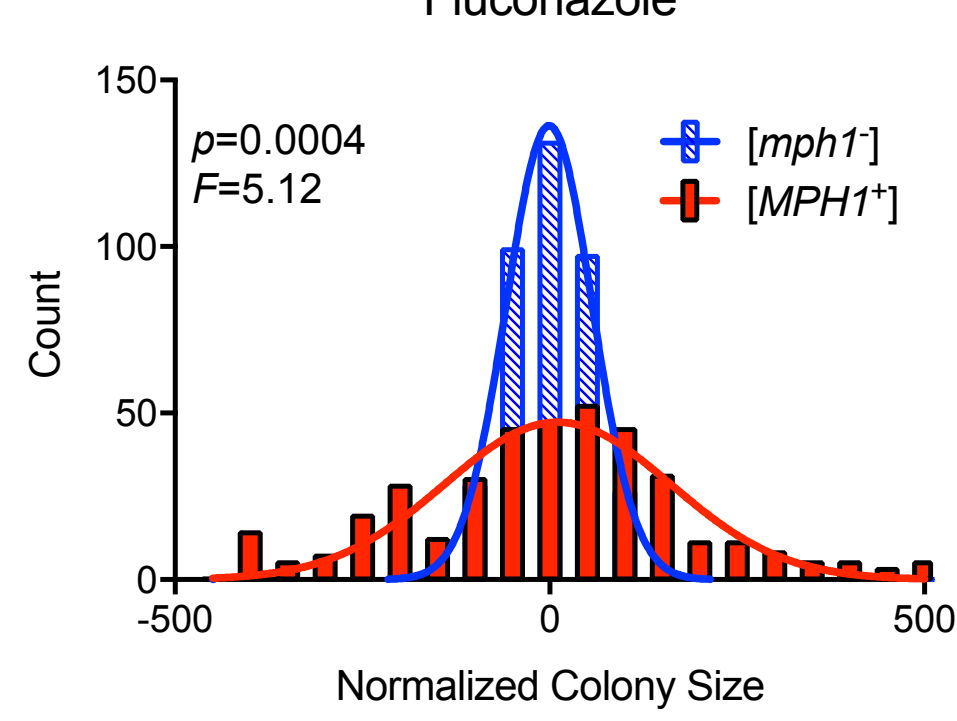

G

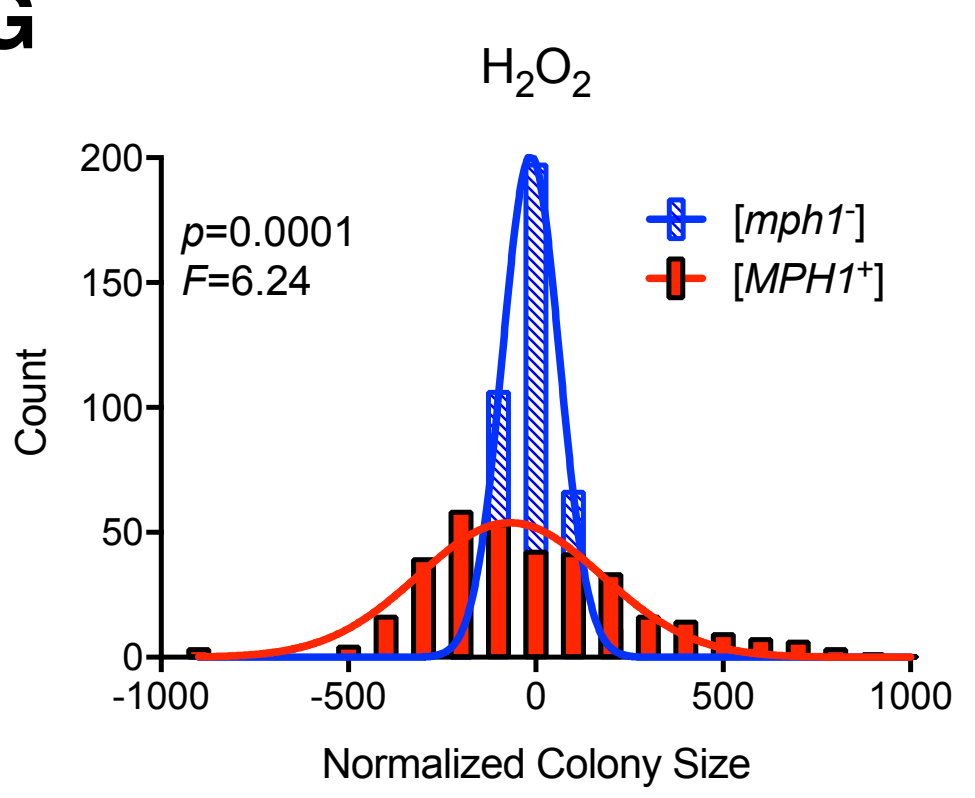




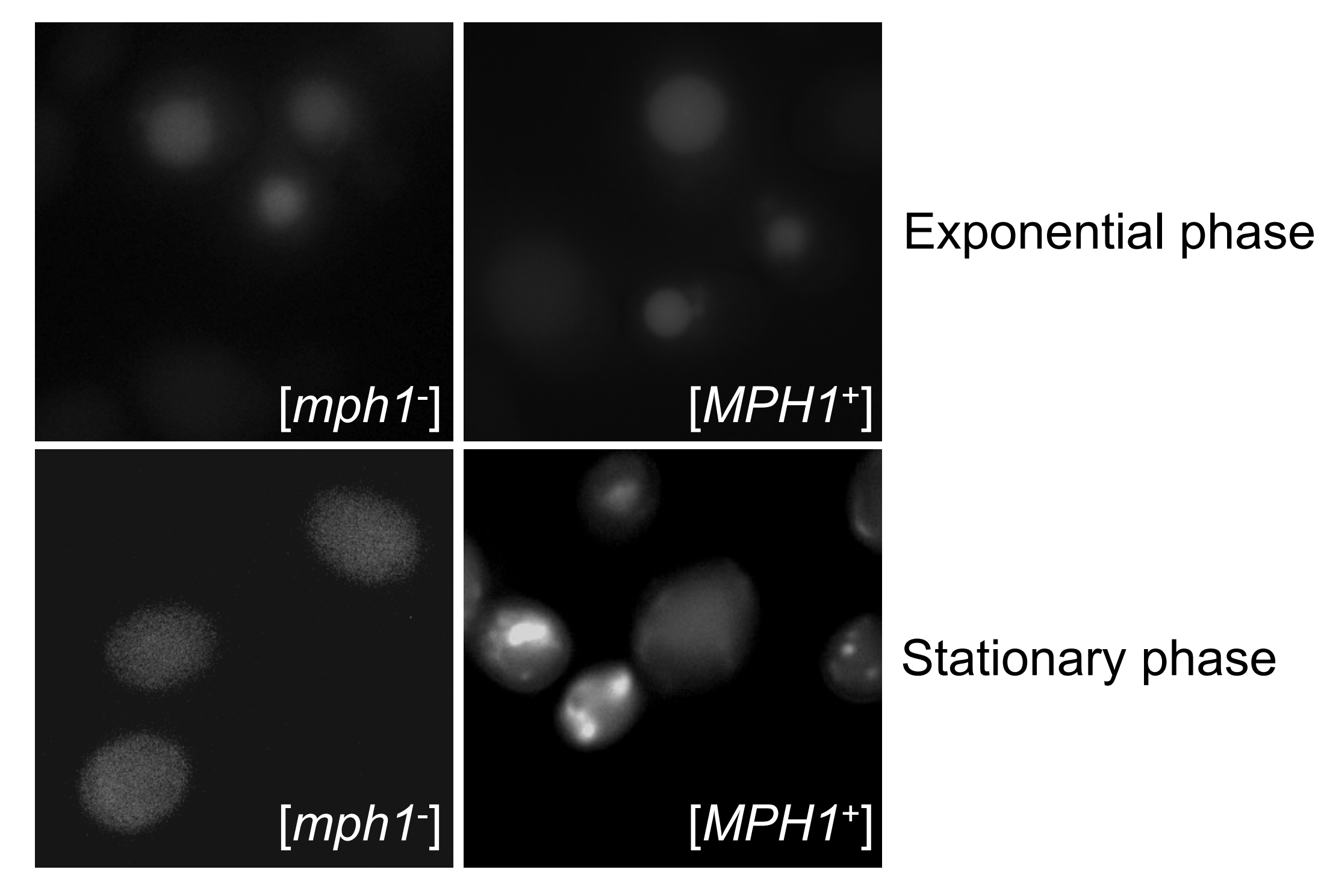

Figure S1

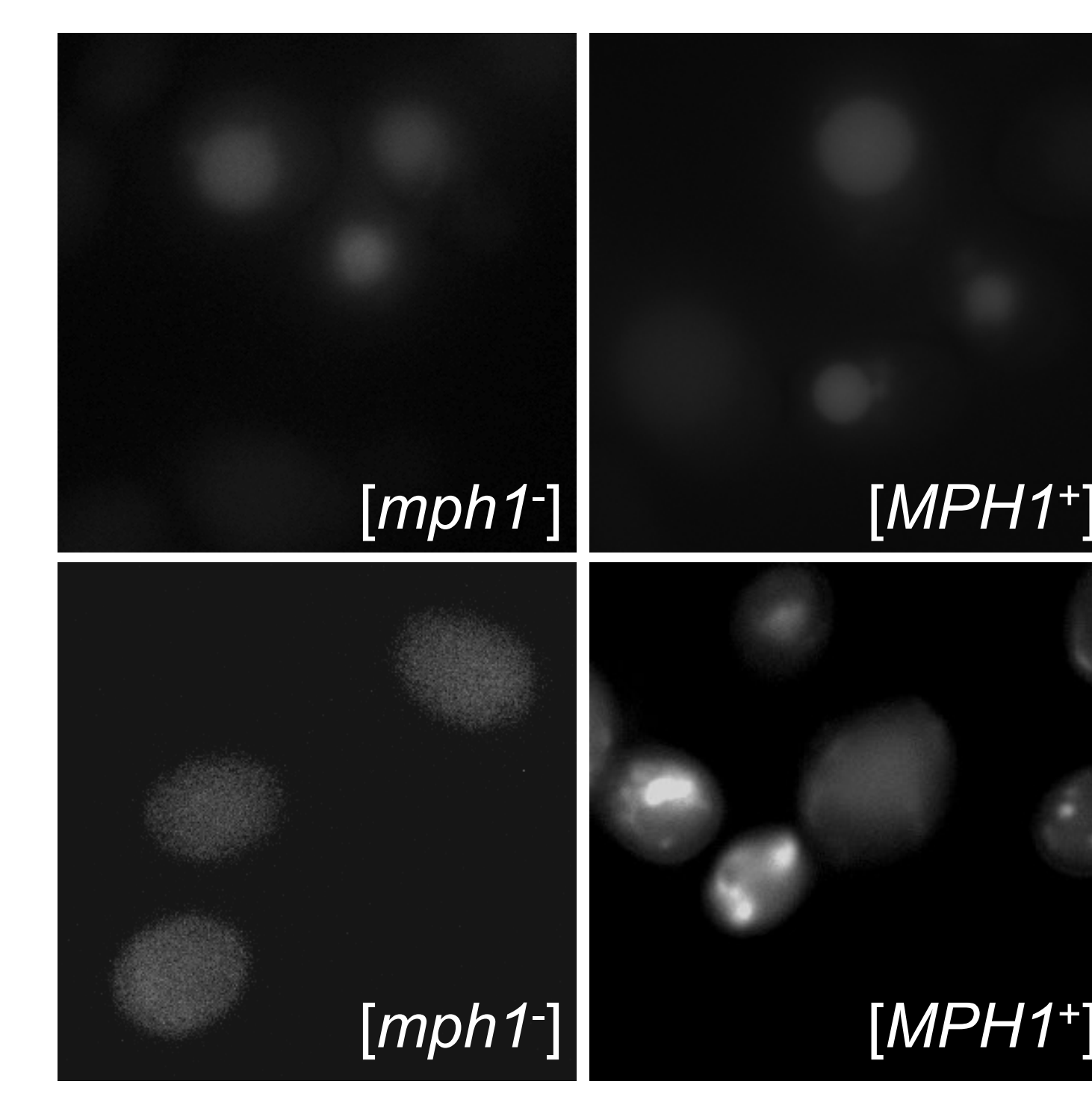

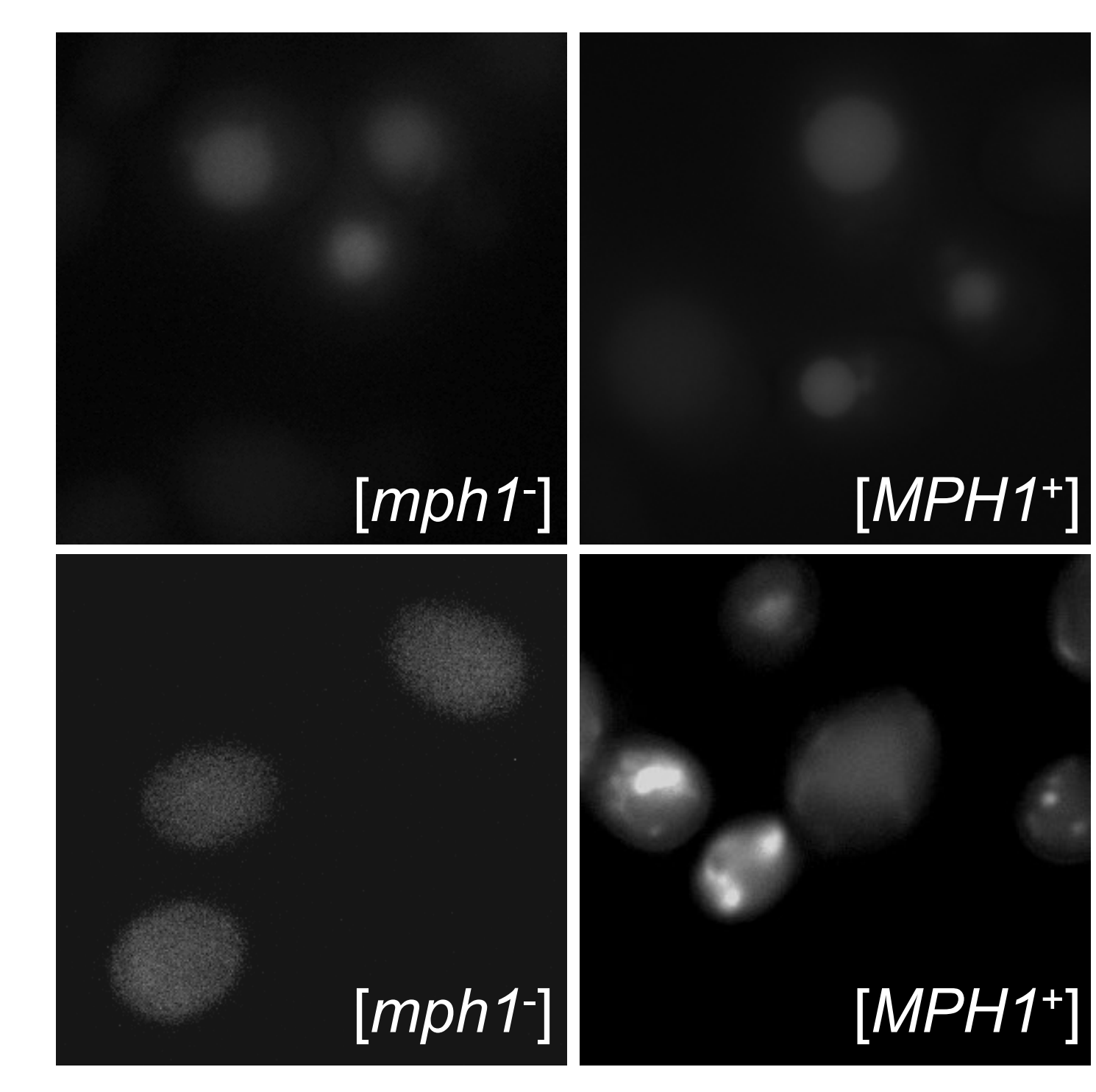

Exponential phase

Stationary phase

.

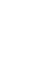

Exponential phase

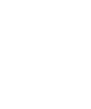

\section{.}

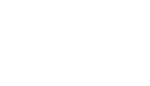

.
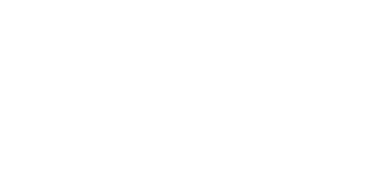
A

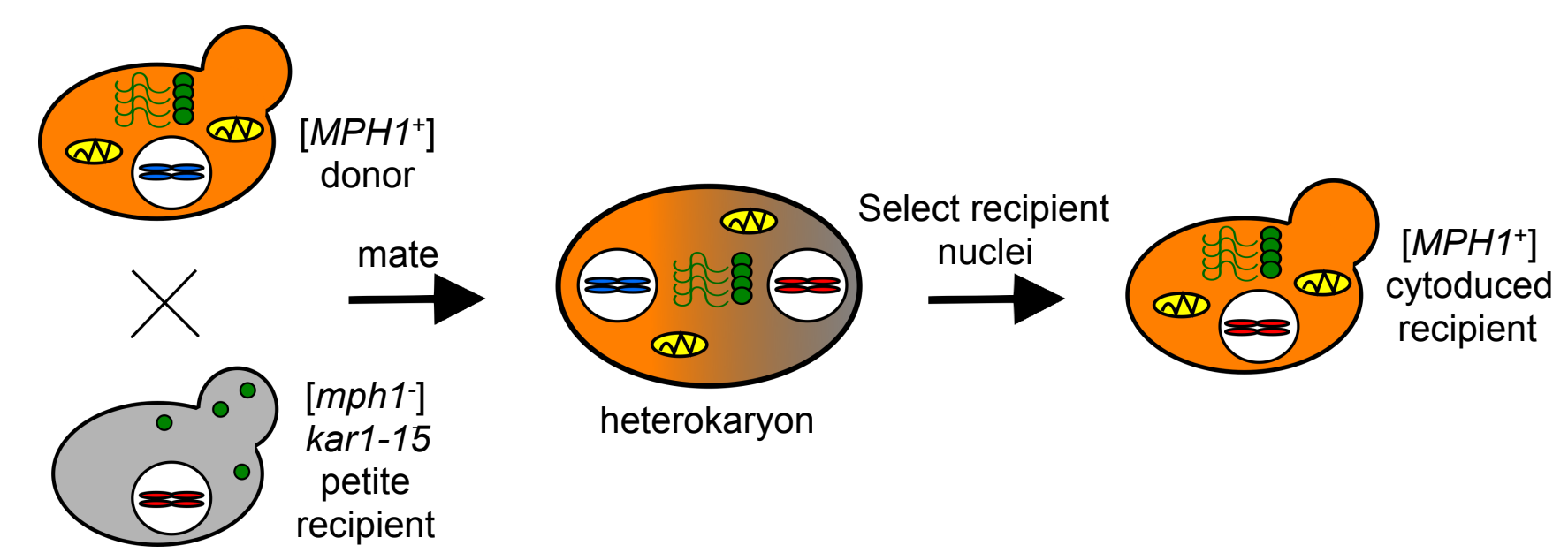

B
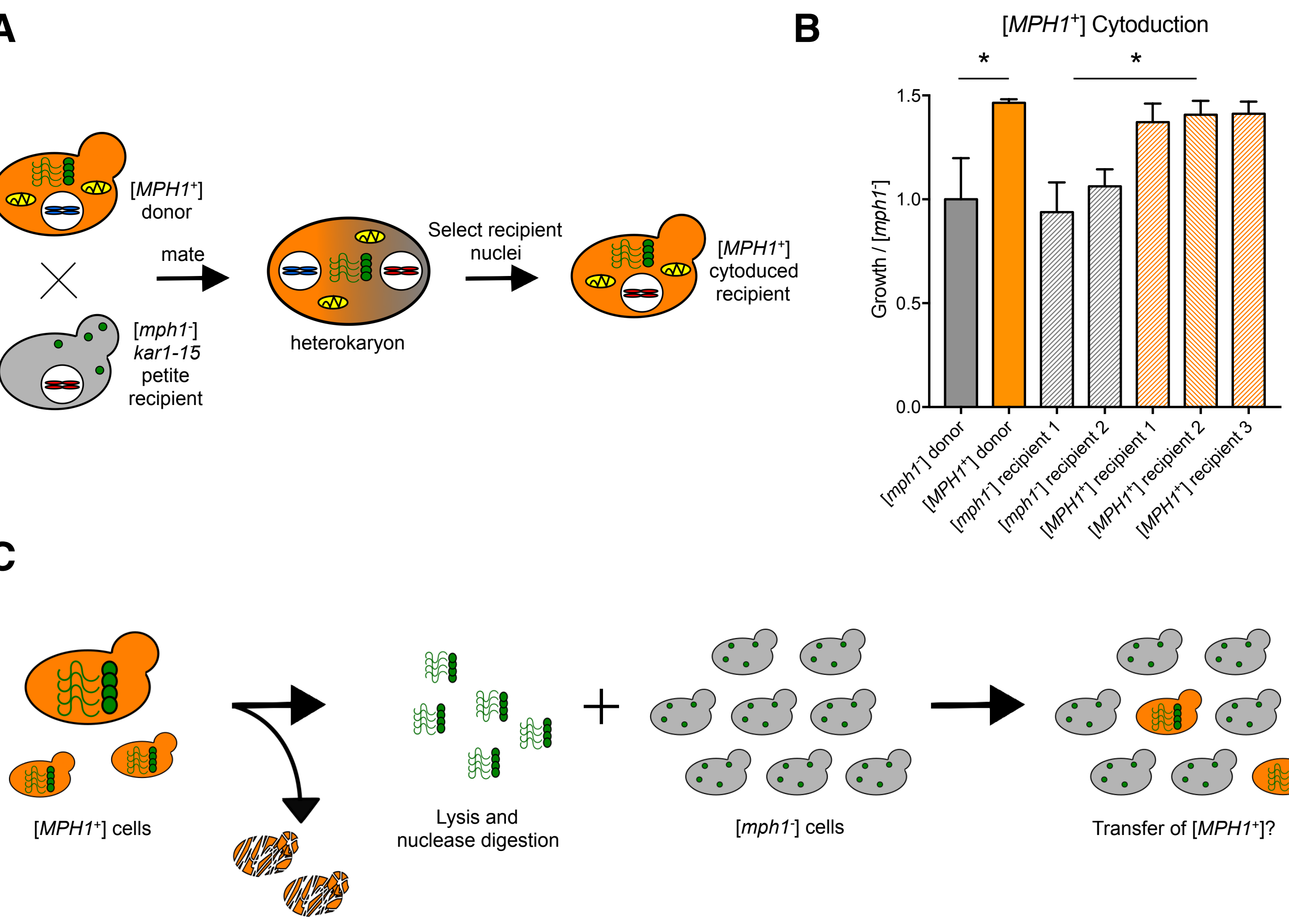

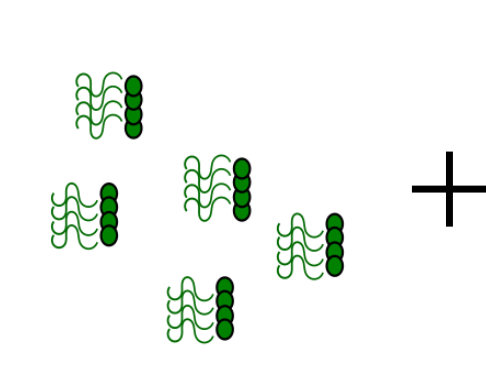

Lysis and nuclease digestion

$\left[\mathrm{MPH}^{+}\right]$cells
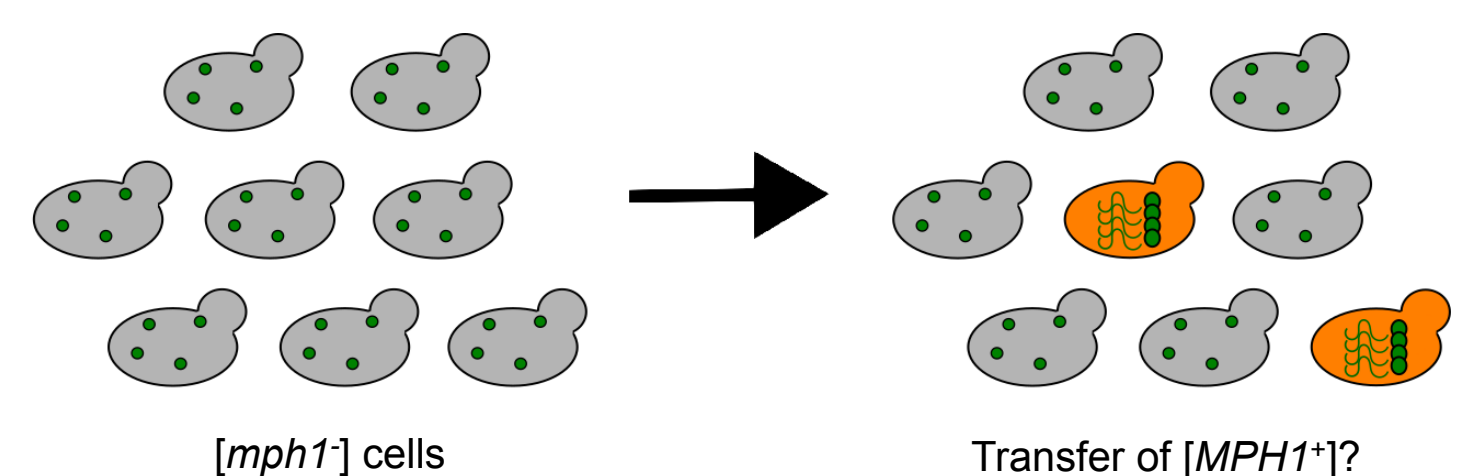

Transfer of $\left[\mathrm{MPH}^{+}\right]$? 


\section{Figure S3}

A

Counter-selectable markers Essential gene

URA3 CAN1 PCM1

$\downarrow$ GCR event

Canavanine, 5-FOA resistant

B

GCR mutagenesis

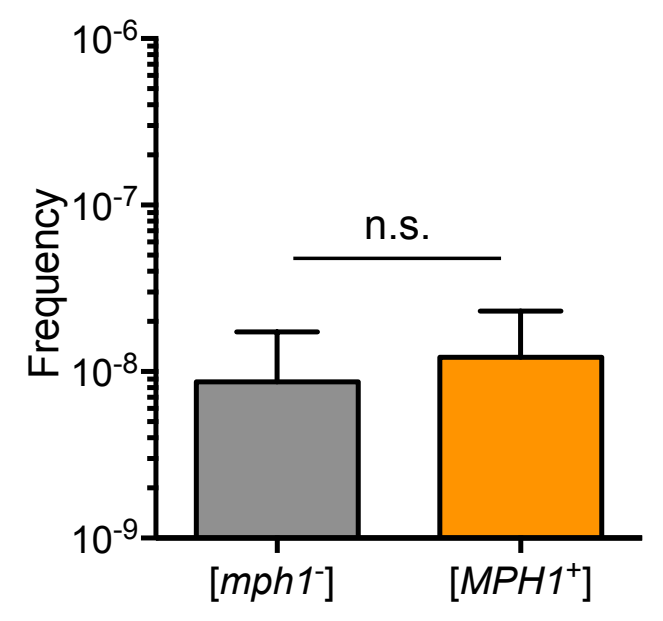


Figure S4
\[ \text { Homologous Recombination } \]
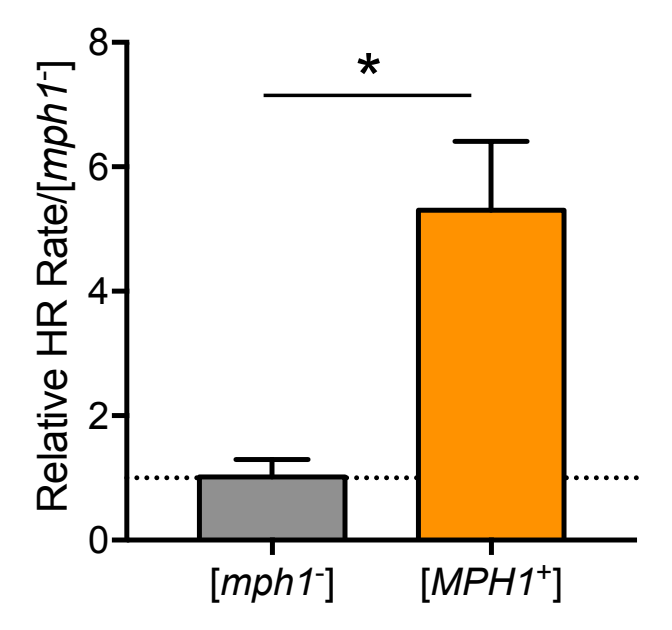


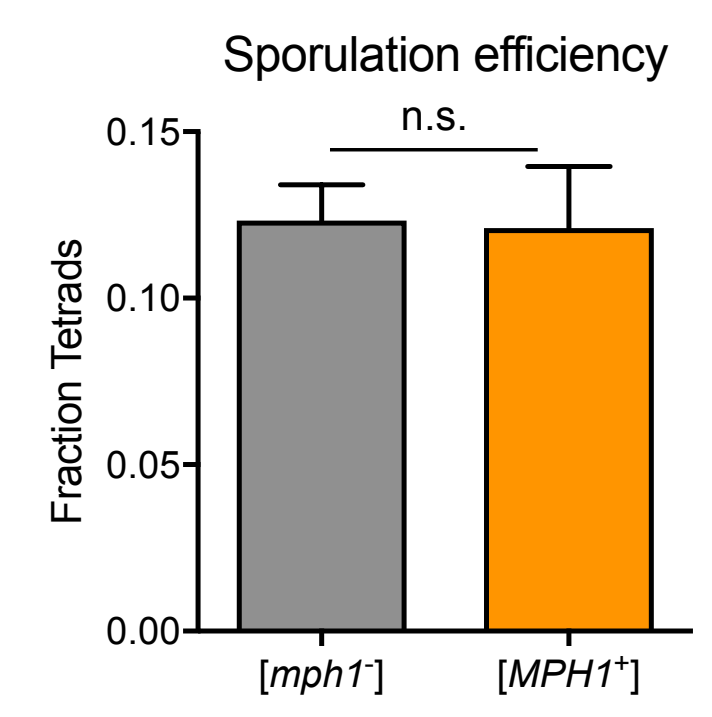




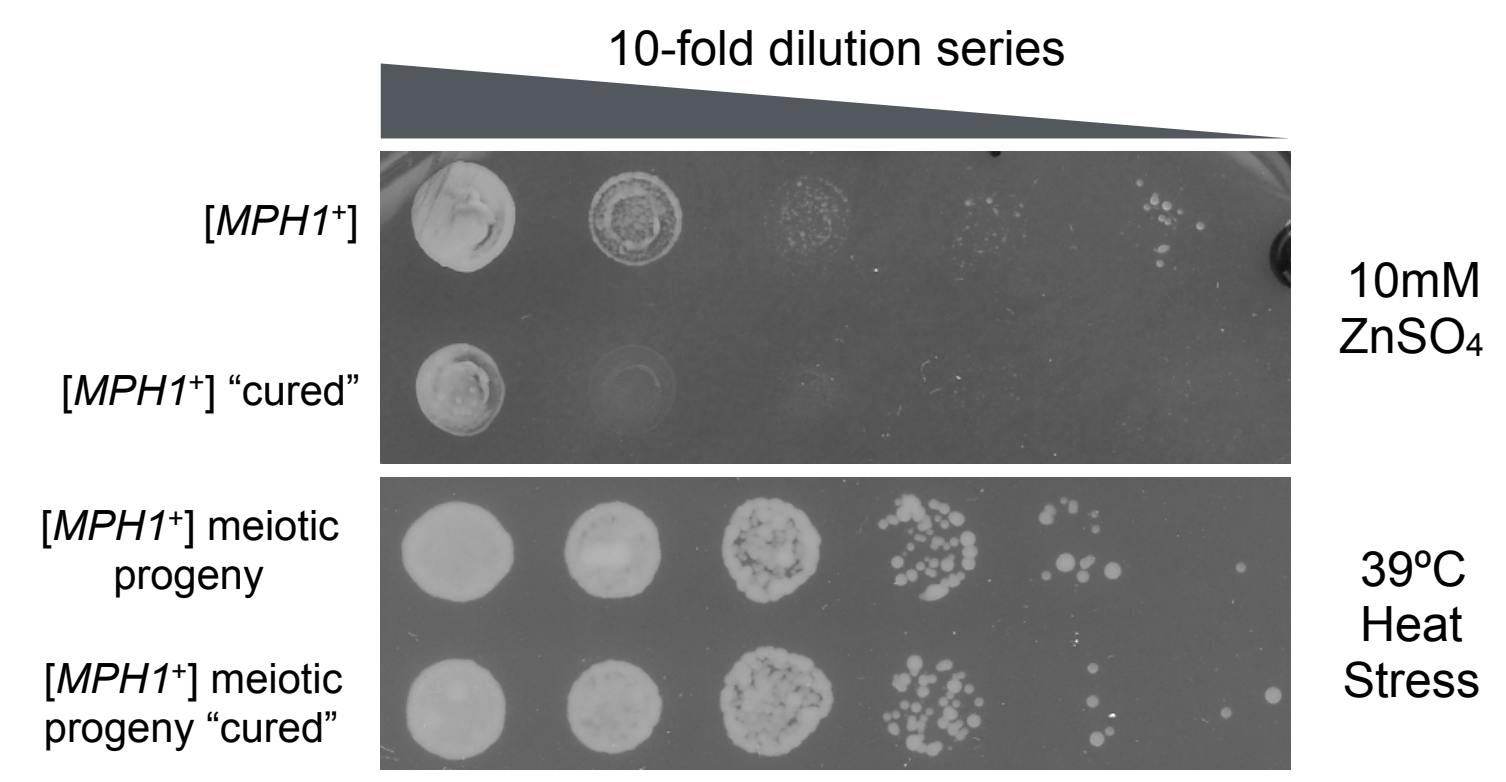

Heat

Stress

$\left[\mathrm{MPH}^{+}\right]$meiotic

progeny "cured"

$10 \mathrm{mM}$

$\mathrm{ZnSO}_{4}$

\section{C}

Stros

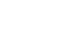




\begin{tabular}{|c|c|}
\hline Strain & Source \\
\hline mph1-Q603D-3Flag::HIS3 & Xiaolan Zhao lab (MSKCC) \\
\hline BY4742 rad5 $\Delta$ & Yeast MATa deletion library \\
\hline BY4742 rad51 & Yeast MATa deletion library \\
\hline$B Y 4742 \operatorname{sgs} 1 \Delta$ & Yeast MATa deletion library \\
\hline BY4742 srs2 $\Delta$ & Yeast MATa deletion library \\
\hline BY4742 mhf1A & Yeast MATa deletion library \\
\hline BY4742 mhf2A & Yeast MATa deletion library \\
\hline BY4742 chl1 & Yeast MATa deletion library \\
\hline BY4742 exo1A & Yeast MAT $\alpha$ deletion library \\
\hline BY4742 mgm101ه & Yeast MATa deletion library \\
\hline$B Y 4742 m s h 2 \Delta$ & Yeast MAT $\alpha$ deletion library \\
\hline BY4742 msh6s & Yeast MATa deletion library \\
\hline$B Y 4742$ pso2s & Yeast MAT $\alpha$ deletion library \\
\hline BY4742 s/x4A & Yeast MATa deletion library \\
\hline BY4741 mph1s & Yeast MATa deletion library \\
\hline YJM975 & SGRP collection \\
\hline Mph1-YFP & Xiaolan Zhao lab (MSKCC) \\
\hline MDG1::K.lactisURA3 prion reporter & Chakrabortee et al., 2016 \\
\hline
\end{tabular}




\section{Table S3}

\begin{tabular}{|c|c|c|c|c|}
\hline Genotype & [mph1] Mutation frequency & {$\left[\mathrm{MPH}^{+}\right]$Mutation frequency } & $\begin{array}{l}\text { Mutation fold change by } \\
\text { genotype }\end{array}$ & $\begin{array}{l}\text { Mutation fold change by } \\
\text { prion }\end{array}$ \\
\hline wild-type & $3.33( \pm 1.31) \times 10^{\wedge}(-8)$ & $8.89( \pm 4.44) \times 10^{\wedge}(-9)$ & & 0.3 \\
\hline $\operatorname{rad} 5 \Delta$ & $9.16( \pm 4.89) \times 10^{\wedge}(-7)$ & $9.69( \pm 3.98) \times 10^{\wedge}(-7)$ & 27.5 & 1.1 \\
\hline $\operatorname{rad} 51 \Delta$ & $1.99( \pm 0.36) \times 10^{\wedge}(-6)$ & $1.10( \pm 0.25) \times 10^{\wedge}(-6)$ & 59.6 & 0.6 \\
\hline $\operatorname{sgs} 1 \Delta$ & $2.50( \pm 0.69) \times 10^{\wedge}(-8)$ & $9.28( \pm 3.67) \times 10^{\wedge}(-8)$ & 0.8 & 3.7 \\
\hline $\operatorname{srs} 2 \Delta$ & $3.40( \pm 1.06) \times 10^{\wedge}(-8)$ & $5.67( \pm 0.78) \times 10^{\wedge}(-8)$ & 1.0 & 1.7 \\
\hline$m h f 1 \Delta$ & $1.17( \pm 0.35) \times 10^{\wedge}(-7)$ & $1.00( \pm 0.22) \times 10^{\wedge}(-7)$ & 3.5 & 0.9 \\
\hline$m h f 2 \Delta$ & $7.50( \pm 2.17) \times 10^{\wedge}(-8)$ & $3.00( \pm 1.22) \times 10^{\wedge}(-7)$ & 2.3 & 4.0 \\
\hline $\operatorname{chl} 1 \Delta$ & $2.53( \pm 0.37) \times 10^{\wedge}(-7)$ & $4.06( \pm 1.15) \times 10^{\wedge}(-7)$ & 7.6 & 1.6 \\
\hline exo1 $\Delta$ & $1.14( \pm 0.13) \times 10^{\wedge}(-6)$ & $1.36( \pm 0.12) \times 10^{\wedge}(-6)$ & 34.1 & 1.2 \\
\hline$m g m 101 \Delta$ & $3.62( \pm 2.24) \times 10^{\wedge}(-7)$ & $2.50( \pm 1.52) \times 10^{\wedge}(-8)$ & 10.9 & 0.1 \\
\hline$m s h 2 \Delta$ & $3.18( \pm 0.18) \times 10^{\wedge}(-6)$ & $3.14( \pm 0.19) \times 10^{\wedge}(-6)$ & 95.3 & 1.0 \\
\hline$m s h 6 \Delta$ & $1.73( \pm 0.20) \times 10^{\wedge}(-6)$ & $1.62( \pm 0.09) \times 10^{\wedge}(-6)$ & 51.9 & 0.9 \\
\hline pso2 $\Delta$ & $3.89( \pm 0.98) \times 10^{\wedge}(-7)$ & $1.78( \pm 0.04) \times 10^{\wedge}(-7)$ & 11.7 & 0.5 \\
\hline$s / x 4 \Delta$ & $7.92( \pm 1.62) \times 10^{\wedge}(-8)$ & $8.89( \pm 4.76) \times 10^{\wedge}(-7)$ & 2.4 & 11.2 \\
\hline
\end{tabular}

